\title{
Capping Strategies for Covalent Template-Directed Synthesis of Linear Oligomers using CuAAC
}

Maria Ciaccia, Diego Núñez-Villanueva and Christopher A. Hunter*

Department of Chemistry, University of Cambridge, Lensfield Road, Cambridge CB2 1EW, UK.

\section{Supplementary Information}

Table of contents

Page

General experimental details $\quad$ S2

LCMS methods $\quad$ S3

General procedure for kinetic experiments of CuAAC reactions of $19 \quad$ S4

HPLC chromatograms of CuAAC reaction of 19 without capping azide $\quad$ S5

HPLC chromatograms of CuAAC reaction of $\mathbf{1 9}$ with capping azide $\quad$ S7

General procedure for assessment of product distribution $\quad$ S8

Comparison of product distribution of CuAAC reaction of 27 and $28 \quad$ S8

$\begin{array}{lr}\text { Capping azide relative reactivity assessment } & \text { S9 }\end{array}$

Evidence of identity of ZIP product $24 \quad 510$

$\begin{array}{lr}\text { Variable Temperature }{ }^{\mathbf{1}} \mathbf{H}-\mathrm{NMR} \text { of } \mathbf{2 4} & \text { S12 }\end{array}$

Parallel/antiparallel ratio of ZIP product with and without capping azide $\quad$ S13

$\begin{array}{lr}\text { Hydrolysis of } \boldsymbol{a} \text {-24. } & \text { S14 }\end{array}$

$\begin{array}{lr}\text { Characterisations } & \text { S15 }\end{array}$

$\begin{array}{lr}\text { References } & \text { S52 }\end{array}$ 


\section{General experimental details}

All reagents and solvents used for the synthesis of the compounds listed below were bought from commercial sources and used without further purification. Dry THF and $\mathrm{CH}_{2} \mathrm{Cl}_{2}$ were taken from a solvent purification system (Pure Solv ${ }^{\mathrm{TM}}$, Innovative Technology, Inc.). Anhydrous DMF was purchased from Sigma-Aldrich. Thin layer chromatography was carried out using silica gel 60F (Merck). Flash chromatography was carried out on an automated system (Combiflash Rf+ or Combiflash Rf Lumen) using prepacked cartridges of silica ( $25 \mu$ PuriFlash ${ }^{\circledR}$ Columns). LCMS analysis was performed on either an analytical Agilent HP1200 coupled to an Agilent/Bruker ion trap or on a Waters Acquity H-class UPLC coupled with a single quadrupole Waters SQD2. NMR spectra were recorded on Bruker $400 \mathrm{MHz}$ DPX400, $400 \mathrm{MHz}$ AVIII400, $500 \mathrm{MHz}$ DCH cryoprobe or $500 \mathrm{MHz}$ TCI Cryoprobe spectrometer and were internally referenced to the residual proton solvent signal. All chemical shifts $(\delta)$ are quoted in ppm and coupling constants given in Hz. Abbreviations for signals multiplicity are: s (singlet), bs (broad singlet), d (doublet), t (triplet), q (quadruplet), m (multiplet). FT-IR spectra were measured on a PerkinElmer Spectrum One spectrometer equipped with an ATR cell. Melting points were measured in a Mettler Toledo MP50 Melting Point System. HRMS analysis was carried out on a Waters LCT Premier equipped with a TOF mass analyser and $\mathrm{W}$ optics for enhanced resolution, using $50 \%$ aqueous acetonitrile with $0.25 \%$ formic acid as mobile phase. 


\section{LCMS methods}

Chromatographic separation was achieved using a CORTECS C18+, $2.7 \mu \mathrm{m}, 4.6 \times 50 \mathrm{~mm}$ column (Waters) for methods A, B and C and an ACQUITY UPLC CSH C18 Column, $130 \AA, 1.7 \mu \mathrm{m}, 2.1 \times 50 \mathrm{~mm}$ (Waters) for method D. Eluents used were $\mathrm{H}_{2} \mathrm{O}+0.1 \%$ formic acid as solvent $\mathrm{A}$ in all the methods and THF $+0.1 \%$ formic acid (methods $\mathrm{A}$ and $\mathrm{B}$ ) or $\mathrm{ACN}+0.1 \%$ formic acid (methods $\mathrm{C}$ and $\mathrm{D}$ ) as solvent $\mathrm{B}$.

\section{LCMS method A}

Eluent B was linearly increased from 58 to $78 \%$ B in 6 minutes and then up to $98 \%$ over 2 minutes. Flow rate was $0.8 \mathrm{ml} / \mathrm{min}$ and the column was kept at room temperature (ca. $\left.21^{\circ} \mathrm{C}\right)$.

\section{LCMS method B}

Eluent B was linearly increased from 57 to $60 \%$ B in 8 minutes and then up to $98 \%$ over 2 minutes. Flow rate was $0.8 \mathrm{ml} / \mathrm{min}$ and the column was kept at room temperature (ca. $\left.21^{\circ} \mathrm{C}\right)$.

\section{LCMS method C}

Eluent B was linearly increased from 70 to $95 \%$ in 6 minutes and then held for 2 minutes. Flow rate was $1 \mathrm{ml} / \mathrm{min}$ and the column was kept at room temperature (ca. $21^{\circ} \mathrm{C}$ ).

\section{LCMS method D}

Eluent B was linearly increased from 5 to $100 \%$ in 2 minutes and then held for 1 minute. Flow rate was $0.6 \mathrm{ml} / \mathrm{min}$ and column temperature was $40^{\circ} \mathrm{C}$. Injection volume was $2 \mu \mathrm{L}$. 


\section{General procedure for kinetic experiments of CuAAC reactions of 19}

The calculated amount from stock solutions of pre-ZIP intermediate, capping azide (when present) and $\mathrm{Cu}(\mathrm{I})$ catalyst were transferred in this order under nitrogen in a double neck flask containing dry THF. Catalyst stock solutions were prepared by mixing equal moles of $\mathrm{Cu}\left(\mathrm{CH}_{3} \mathrm{CN}\right)_{4} \mathrm{PF}_{6}$ and TBTA (CuTBTA). All stock solutions were freshly prepared in dry THF and used under a stream of nitrogen. Reaction progress was followed by injecting $4 \mu \mathrm{l}$ of unquenched reaction mixture collected at specific time intervals in the LCMS and observing the change in the peak areas of reagents and products by UV ( $\lambda 280$ $\mathrm{nm})$. Peaks identity was assigned based on the corresponding mass spectra, order of appearance and retention time. Two different gradients were used for monitoring CuAAC reaction of 19 in the absence $(\operatorname{method} A)$ and in the presence of the capping azide (method $B)$. Linearity of the methods was assessed by injecting increasing concentrations of a quenched reaction mixture containing all the major species followed during the experiment. Method D was used for monitoring reaction of $\mathbf{2 7}$ and $\mathbf{2 8}$ in the absence of capping agent. 


\section{HPLC chromatograms of CuAAC reaction of pre-ZIP intermediate 19 without capping azide}

Figure S1(a) shows some of the products that can be formed from CuAAC reaction of 19 $(25 \mu \mathrm{M})$ in the presence of CuTBTA $(50 \mu \mathrm{M})$. HPLCUV chromatograms $(\lambda 280 \mathrm{~nm})$ obtained by injecting aliquots of the unquenched reaction mixture collected at different times and the mass spectra of relevant peaks are given in Figure S1(b) and S1(c), respectively. Several reactive intermediates can be formed by intermolecular reaction of starting material (black dot) and/or the product of the intramolecular ZIP reaction (red dot). Such intermediates can react in intramolecular fashion forming kinetically stable macrocycles (the two cyclic species on the right end of Figure S1(a)). The bottom spectrum in Figure S1(c) is consistent with the formation of the intramolecular ZIP product since it has the same molecular ion of the starting material (1566.5) and an isotopic pattern consistent with a singly charged species (see inset). The mass spectra corresponding to the three peaks with retention time between 3 and 4.5 minutes in the middle chromatogram in (b) (blue dots and light blue square) are comparable and the middle spectrum in (c) is a representative example. Although the exact structure of these species was not determined, all the corresponding mass spectra have a signal at $m / z=1045.5$ that is consistent with the triply charged ion of a molecule with a mass equal to two times that of the starting material. The 1566.5 ion is also present and the isotopic pattern is that of a doubly charged species (see inset), as expected for the product of an intramolecular reaction between two molecules of starting material and/or ZIP product. A macrocyclic structure is proposed for the peak with retention time around 3.2 minutes (light blue square) because this species accumulates over time and is kinetically stable. The peak with retention time around 4.5 minutes in the bottom chromatogram in (b) was tentatively assigned to a macrocyclic structure formed by three molecules of ZIP product (light blue hexagon) since it also accumulates over time and the corresponding mass spectrum (top trace in (c)) has ions with $m / z=940.9$ and $m / z=1175.95$ that are consistent with an ion having mass equal to three times that of the starting material and 5 or 4 charges, respectively. The 1566.5 ion is also present and the isotopic pattern is that of a triply charged species (see inset), as expected for the product of an intramolecular reaction between two molecules of starting material and/or ZIP product. 


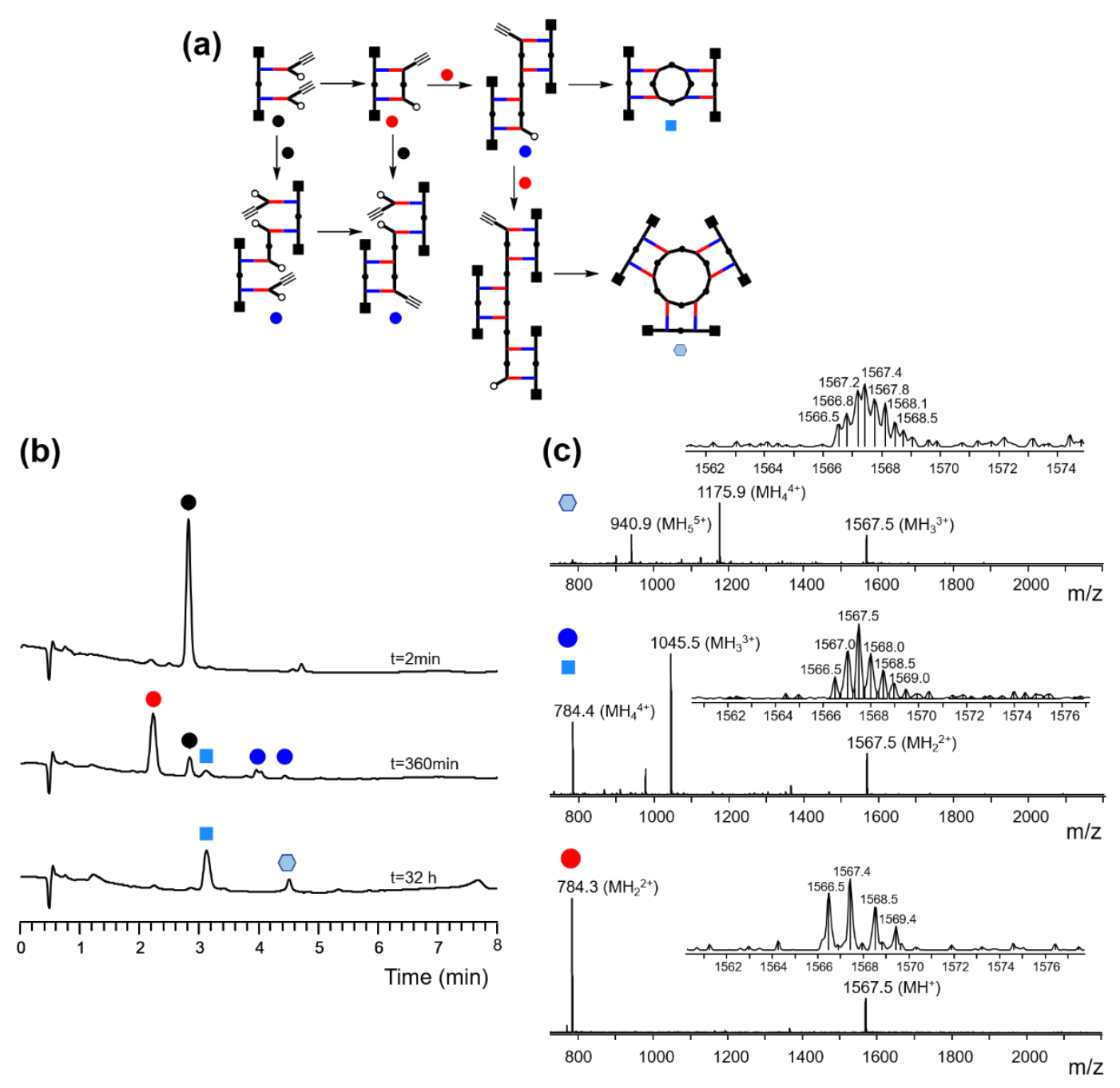

Figure S1. (a) Products of CuAAC reaction of $19(25 \mu \mathrm{M})$ and CuTBTA $(50 \mu \mathrm{M})$. (b) HPLC chromatograms $(\lambda 280 \mathrm{~nm})$ obtained by injecting aliquots of unquenched mixture collected at different times. (c) Mass spectrum of peak at 2.3 minutes (red dot) is given in the bottom trace, a representative example of the spectra corresponding to peaks between 3 and 4.5 minutes is shown in the middle chromatogram (blue dots and light blue square) is shown in the middle trace and the spectrum of the peak at 4.5 minutes in the bottom chromatogram (light blue hexagon) is shown in the top trace. HPLC separation was achieved using method $A$. 


\section{HPLC chromatograms of CuAAC reaction of 19 with $2.5 \mathrm{mM}$ and $50 \mathrm{mM}$ capping}

azide

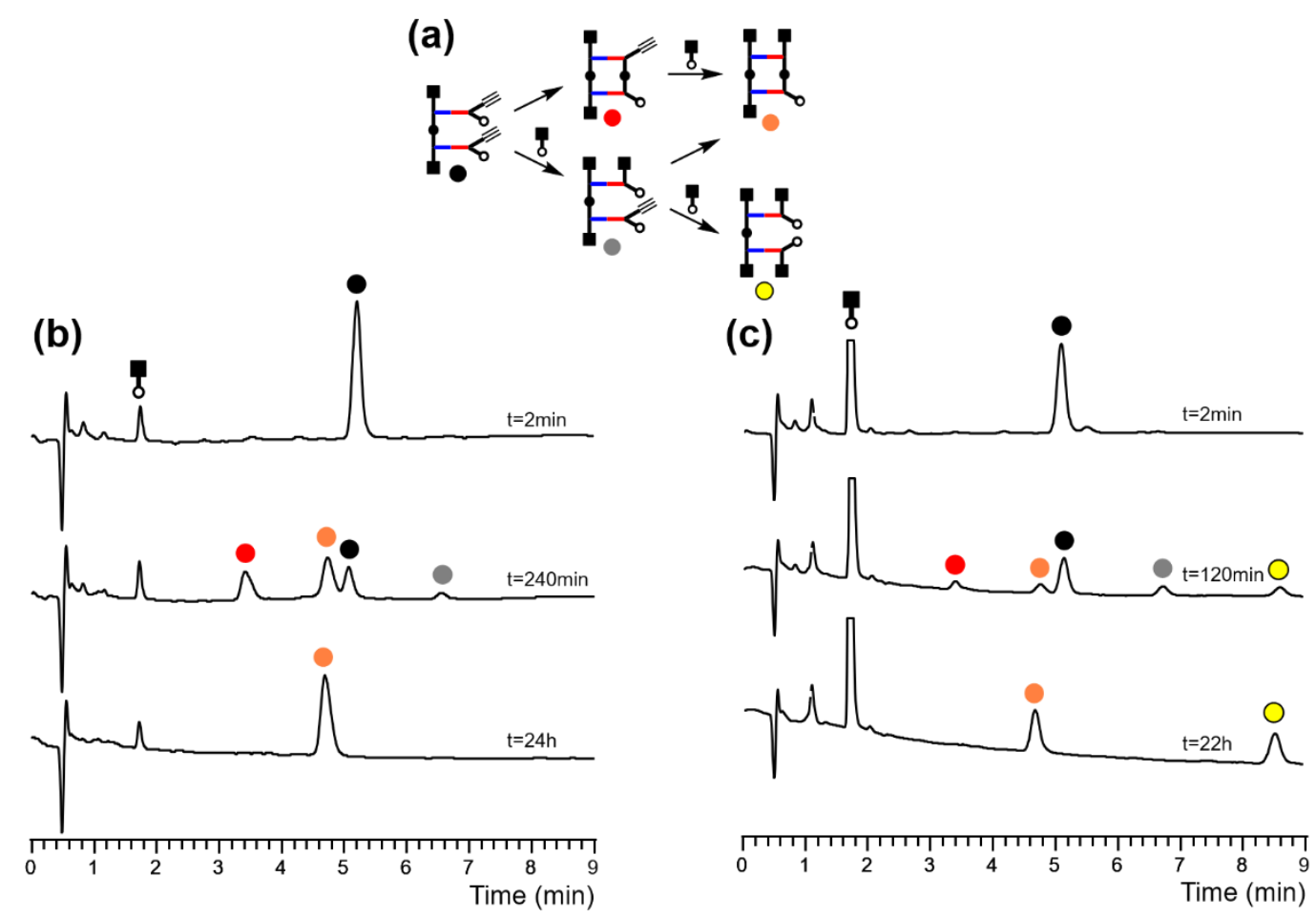

Figure S2. (a) Products of CuAAC reaction of 19 and capping azide. (b) HPLC-UV chromatograms ( $\lambda 280$ $\mathrm{nm})$ obtained by injecting aliquots of unquenched mixture of the CuAAC reaction of $19(25 \mu \mathrm{M})$ and capping azide $(2.5 \mathrm{mM})$ in the presence of CuTBTA $(50 \mu \mathrm{M})$; (c) HPLC-UV chromatograms $(\lambda 280 \mathrm{~nm})$ obtained by injecting aliquots of unquenched mixture of the CuAAC reaction of $19(25 \mu \mathrm{M})$ and capping azide $(50 \mathrm{mM})$ in the presence of CuTBTA $(50 \mu \mathrm{M})$. HPLC separation was achieved using method $B$. 
General procedure for assessing final product distribution with increasing capping azide

The relative amount of intermolecular and intramolecular products obtained from CuAAC reaction of pre-ZIP compounds 19, 27 and 28 was estimated using the following general procedure: the calculated amount from stock solutions of pre-ZIP intermediate, capping azide and $\mathrm{Cu}(\mathrm{I})$ catalyst were transferred in this order under nitrogen in a double neck flask containing dry THF. Catalyst stock solutions were prepared by mixing equal moles of $\mathrm{Cu}\left(\mathrm{CH}_{3} \mathrm{CN}\right)_{4} \mathrm{PF}_{6}$ and TBTA. All stock solutions were freshly prepared in dry THF and used under a stream of nitrogen. Product distribution was assessed by the ratio of HPLC peak areas ( $\lambda 280 \mathrm{~nm}$ ) obtained by injecting in the LCMS $4 \mu 1$ of unquenched reaction mixture collected after 3-4 hours (until complete consumption of reagent and all the intermediates). Peaks identity was assigned based on the corresponding mass spectra, order of appearance and retention time. Different gradients were used for analysing the product distribution obtained by CuAAC reaction of 19 and 27 (method $B$ ) and 28 $(\operatorname{method} C)$.

Comparison of product distribution of $\mathrm{CuAAC}$ reaction of 16 and 18 without capping azide

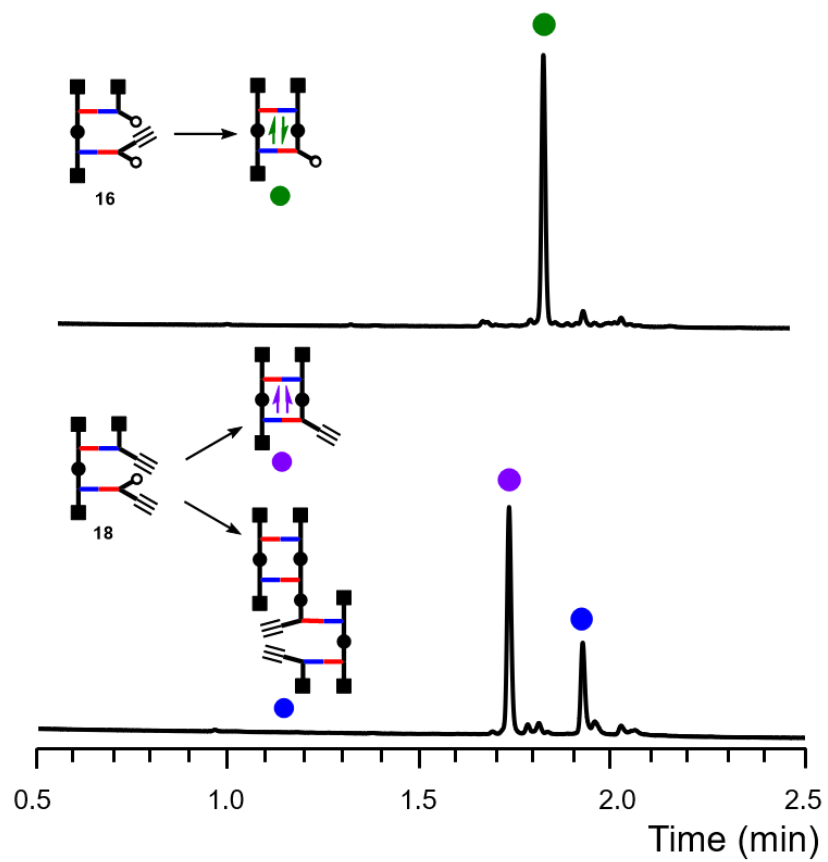

Figure S3. Comparison of HPLC-UV traces of the products obtained from CuAAC reaction of $50 \mu \mathrm{M} 27$ (top trace) and 28 (bottom trace) in the presence of $50 \mu \mathrm{M}$ CuTBTA. HPLC separation was achieved using method $D$. 


\section{Competition experiment proving different reactivity of benzyl- and phenyl-azides}

The relative reactivity of benzyl azide and phenyl azide was tested by analysing the product distribution obtained from the reaction in Figure S4(a) via ${ }^{1} \mathrm{H}-\mathrm{NMR}$. Equimolar amounts $(50 \mu \mathrm{M})$ of azides $\mathbf{3 6}$ and $\mathbf{3 7}$, alkyne $\mathbf{3 8}$ and CuTBTA were mixed in THF. A ca. 3:1 ratio of products $\mathbf{3 9}$ and $\mathbf{4 0}$ was determined from the integrals of the corresponding signals in the ${ }^{1} \mathrm{H}-\mathrm{NMR}$ spectrum. Figure S4(b) is the partial ${ }^{1} \mathrm{H}-\mathrm{NMR}\left(500 \mathrm{MHz}, \mathrm{CDCl}_{3}\right)$ of the reaction mixture after full consumption of 38. Diagnostic signals of reagents and products are highlighted in the reaction scheme and in the spectrum. The kinetic profile of the competing CuAAC reactions of $\mathbf{3 6}$ and $\mathbf{3 7}$ with $\mathbf{3 8}$ was simulated using Tenua. The observed product distribution was achieved in the simulation by using a 5:1 ratio of the kinetic constants corresponding to the reaction of $\mathbf{3 7}$ with $\mathbf{3 8}$ and $\mathbf{3 6}$ with $\mathbf{3 8}$ respectively.

(a)

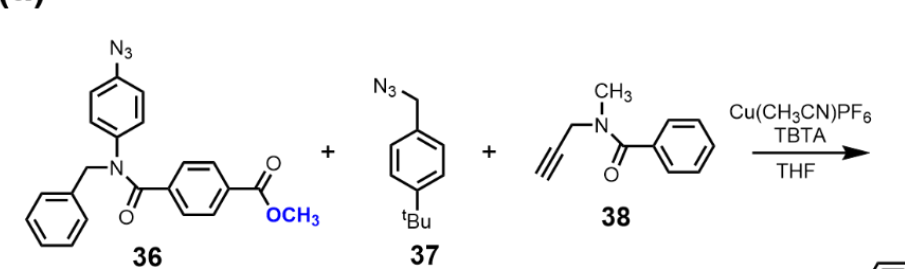

(b)

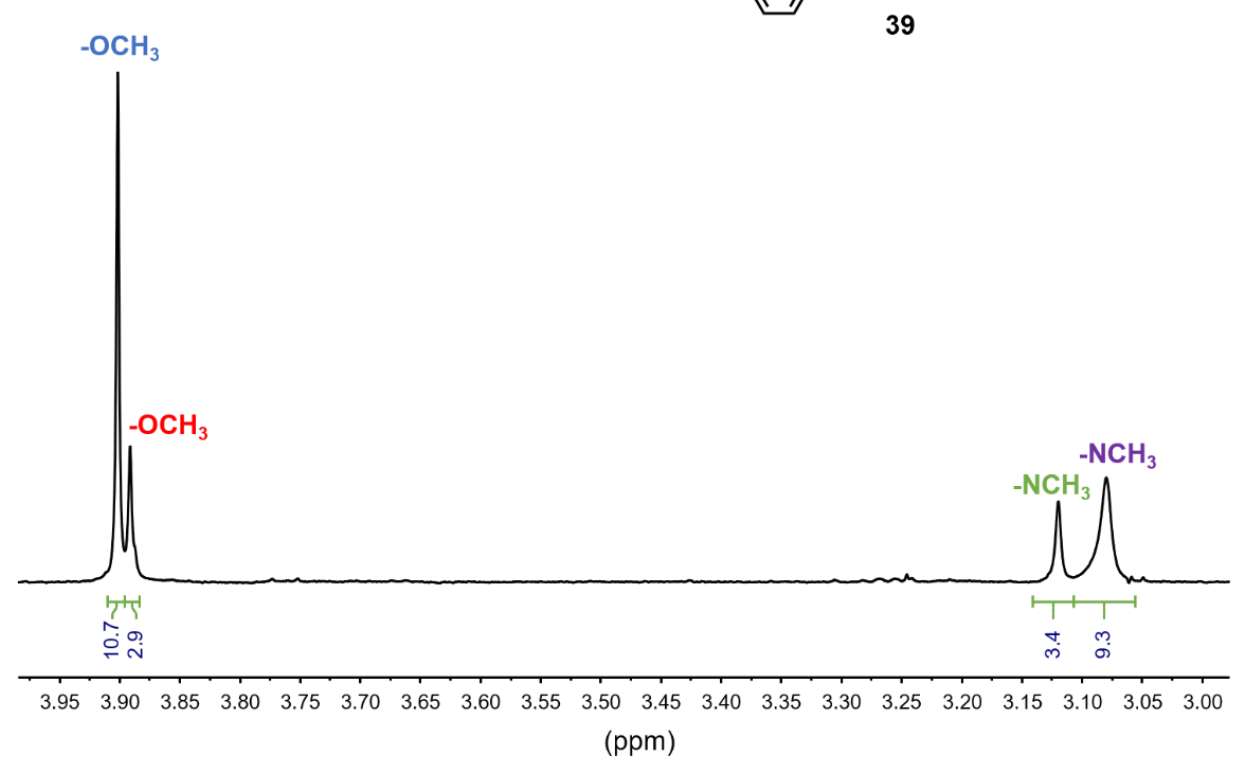

Figure S4. (a) Scheme of competitive CuAAC reaction of azides $\mathbf{3 6}$ and $\mathbf{3 7}$ with alkyne 38. (b) Partial ${ }^{1} \mathrm{H}-\mathrm{NMR}\left(500 \mathrm{MHz}, \mathrm{CDCl}_{3}\right)$ of the crude of the reaction between equimolar amounts of 36, 37 and 38 (50 $\mu \mathrm{M})$ with CuTBTA $(50 \mu \mathrm{M})$ in THF. 


\section{Evidence of formation of ZIP product 24}

Formation of the ZIP product $\mathbf{2 4}$ from CuAAC reaction of $\mathbf{1 9}$ and 4-t-butylbenzyl azide was confirmed by NMR. Figure S5 shows the partial ${ }^{1} \mathrm{H}-\mathrm{NMR}$ spectra of 24 (a) and 19 (b). The proton adjacent to the alkyne is evidenced in $\mathbf{1 9}$ and is absent in the product. Similar conclusion can be obtained by comparison of ${ }^{13} \mathrm{C}-\mathrm{NMR}$ of the two compounds (Figure S6). The spectrum of $\mathbf{2 4}$ (a) lacks the signals in the alkyne region (between 70 and $80 \mathrm{ppm}$ ) that are evident in the spectrum of the starting material 19 (b). The relevant region of the two spectra is shown in the inset.

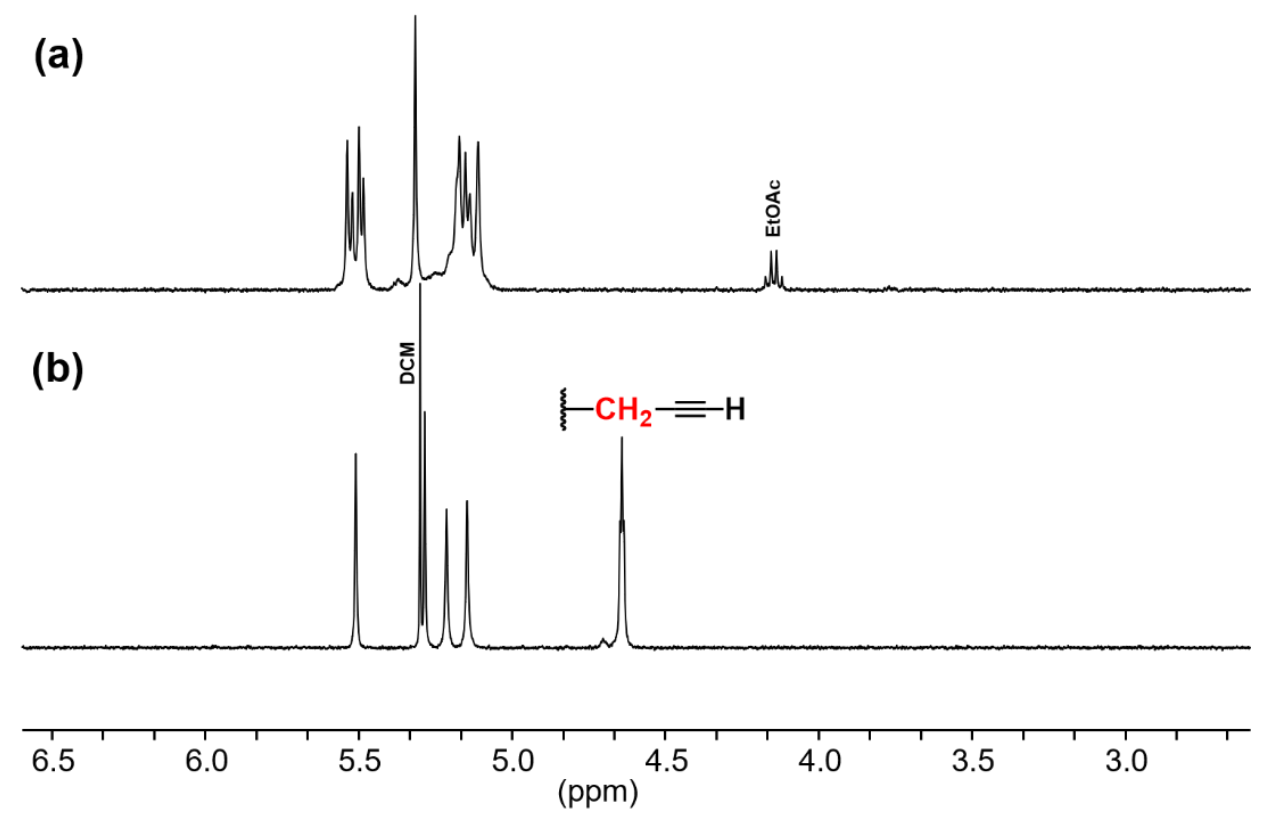

Figure S5. Partial ${ }^{1} \mathrm{H}-\mathrm{NMR}\left(500 \mathrm{MHz}, \mathrm{CDCl}_{3}\right)$ of 24 (a) and 19 (b). 


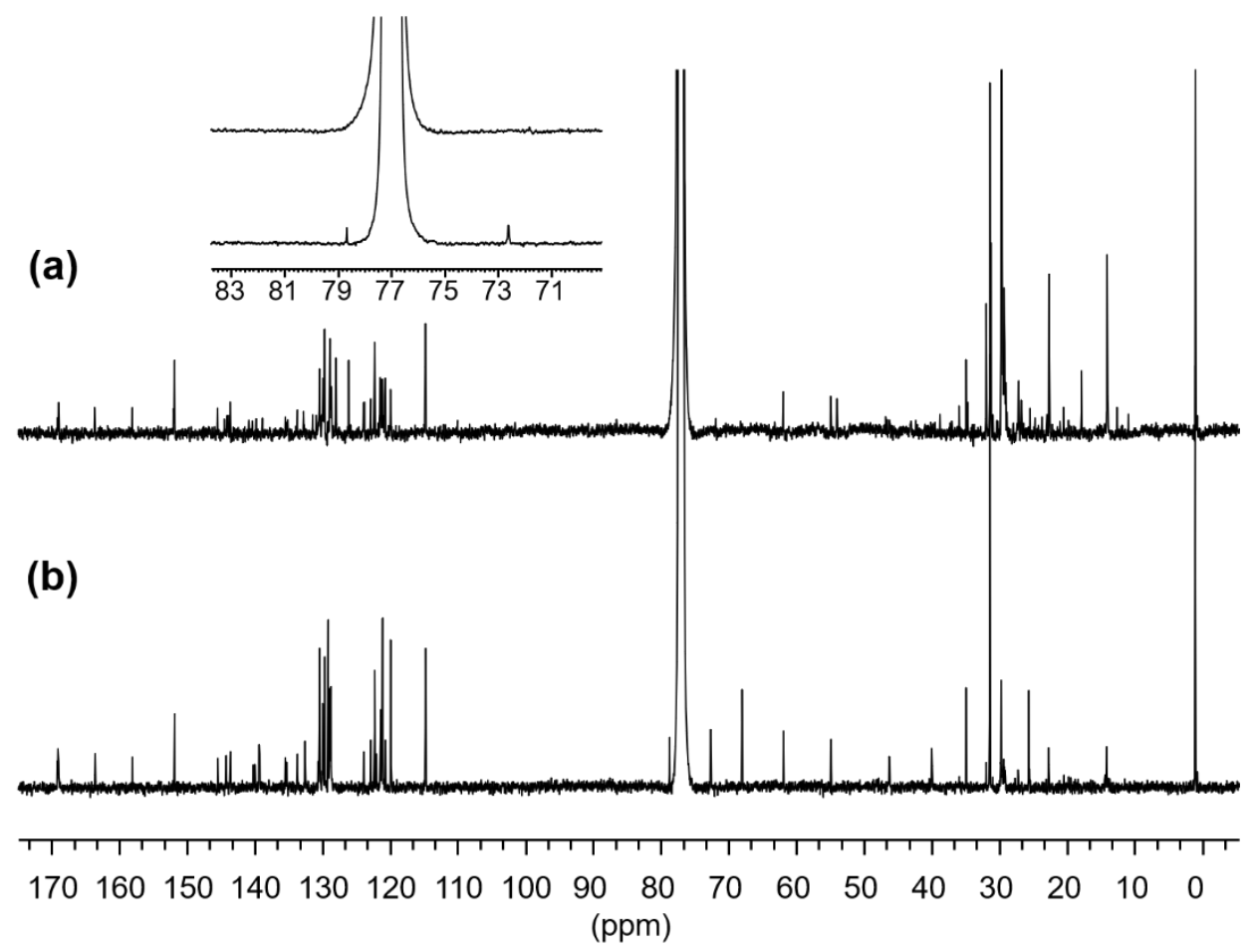

Figure S6. Partial ${ }^{13} \mathrm{C}-\mathrm{NMR}\left(125.7 \mathrm{MHz}, \mathrm{CDCl}_{3}\right)$ of $\mathbf{2 4}$ (a) and 19 (b). The alkyne region of the spectra is evidenced in the inset. 


\section{Variable temperature NMR}

(a)

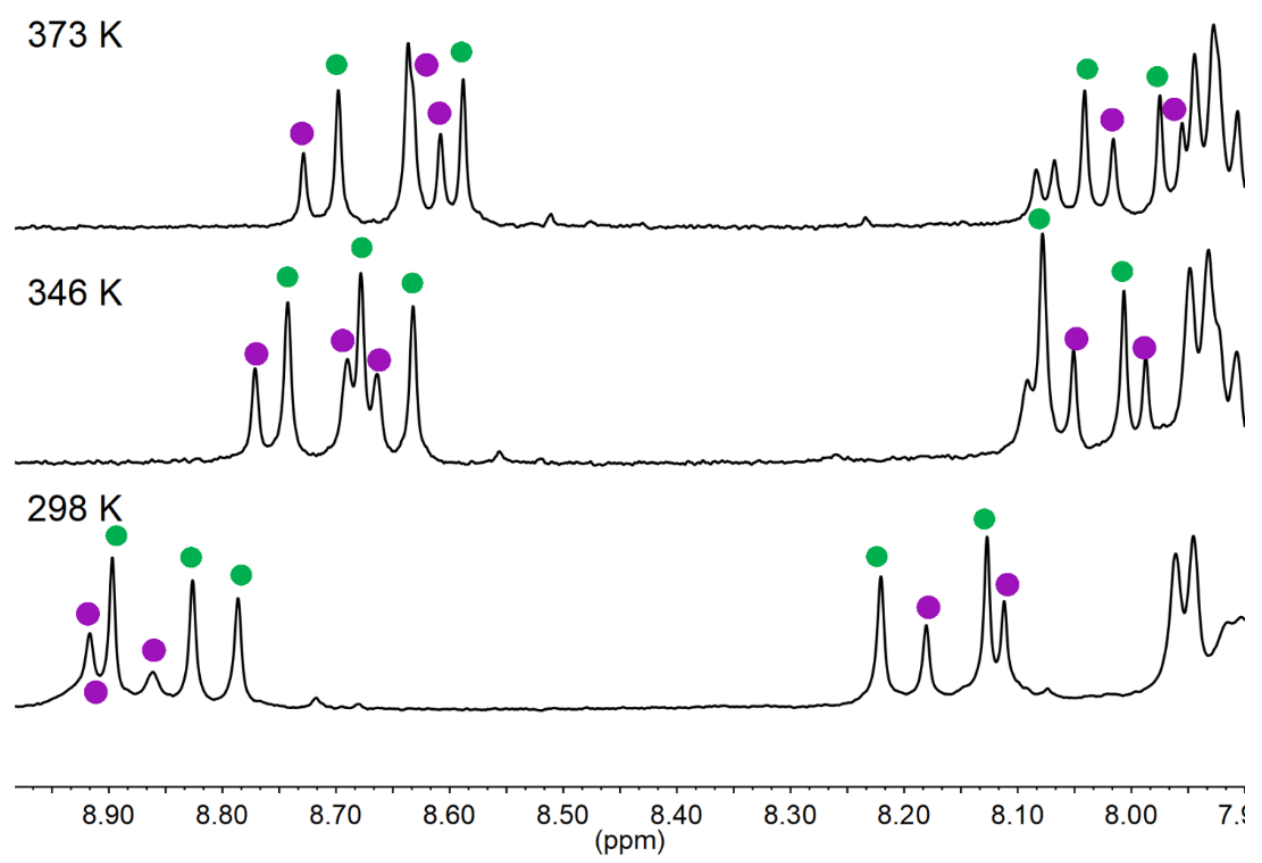

(b)

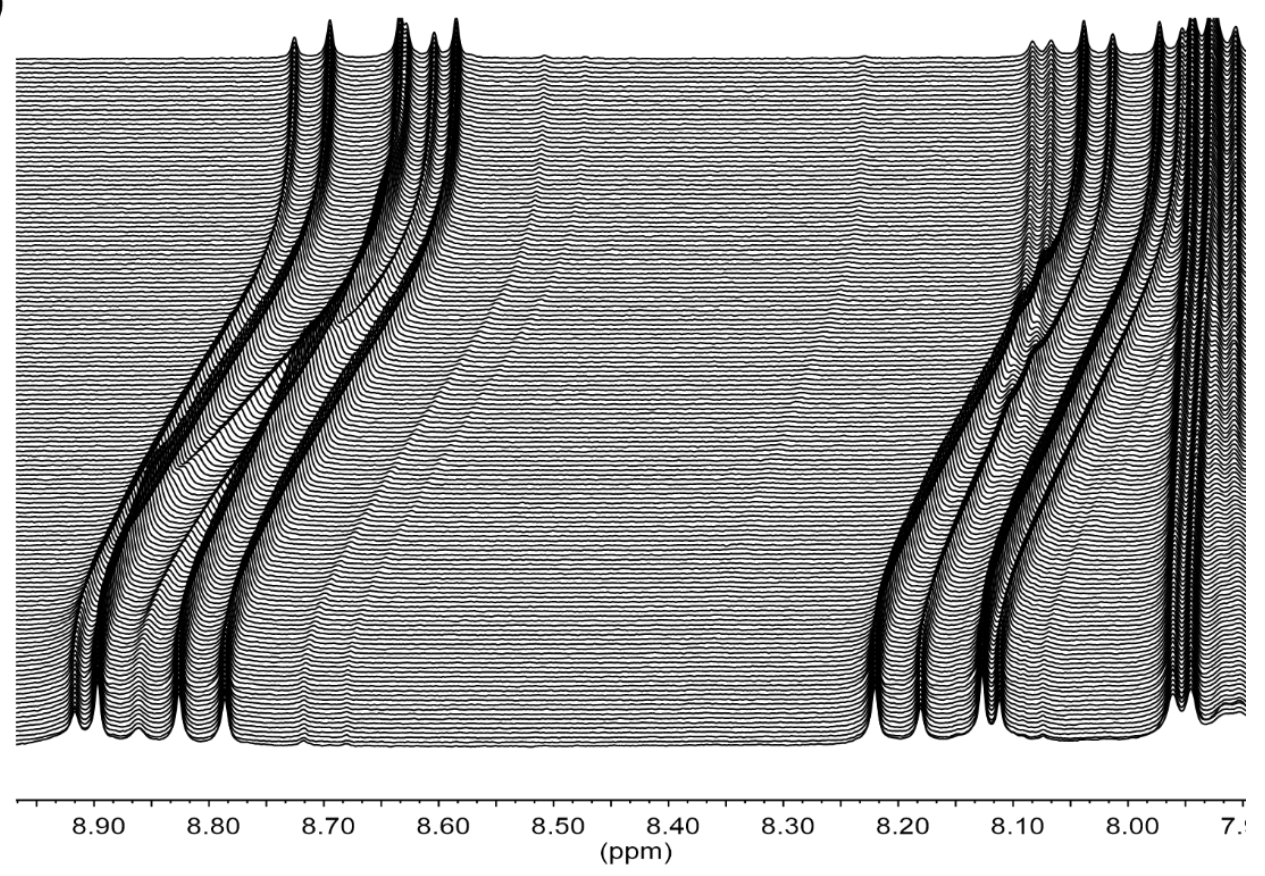

Figure S7. Variable temperature ${ }^{1} \mathrm{H}-\mathrm{NMR}$ experiment (500 MHz, DMSO-d 6 ) of 24 obtained from reaction of $19(25 \mu \mathrm{M})$ with 4 - $t$-butylbenzyl azide $(1.25 \mathrm{mM})$ and CuTBTA $(50 \mu \mathrm{M})$ in THF at room temperature. (a) Shows the spectra recorded at three different temperatures. The triazole signals of the parallel (purple) and antiparallel (green) products are evidenced by the coloured dots. (b) shows the triazole region of all the ${ }^{1} \mathrm{H}-\mathrm{NMR}$ spectra recorded between 298 and $373 \mathrm{~K}$. Temperature was varied continuously with a ramp of $15 \mathrm{~K}$ per minute and two-scans spectra were recorded continuously. 


\section{Parallel/antiparallel ratio of ZIP product with and without capping azide}

The ratio of parallel and antiparallel ZIP product obtained from the CuAAC reaction of 19 depends on the presence and on the amount of capping azide (see main text). The partial ${ }^{1} \mathrm{H}-\mathrm{NMR}$ spectra of the products obtained from the CuAAC reaction of $\mathbf{1 9}(25 \mu \mathrm{M})$ with CuTBTA $(50 \mu \mathrm{M})$ in the presence of 4-t-butylbenzyl azide $(1.25 \mathrm{mM})$ or no capping azide are shown in Figure S8(a) and S8(b), respectively. The amount of antiparallel product $\boldsymbol{a - 2 4}$ obtained in the presence of $1.25 \mathrm{mM}$ cap is $2: 1$ relative to $\boldsymbol{p - 2 4}$ as evidenced by the integrals of the triazole signals in Figure S8(a). In the absence of cap equal amounts of parallel and antiparallel product ( $\boldsymbol{a - 2 0}$ and $\boldsymbol{p}-\mathbf{2 0}$, respectively) are formed as shown in Figure S8(b) as expected considering the proposed mechanism: once the copper acetylide is formed (rate determining step) it cannot re-equilibrate and it reacts in a fast step with an azide.
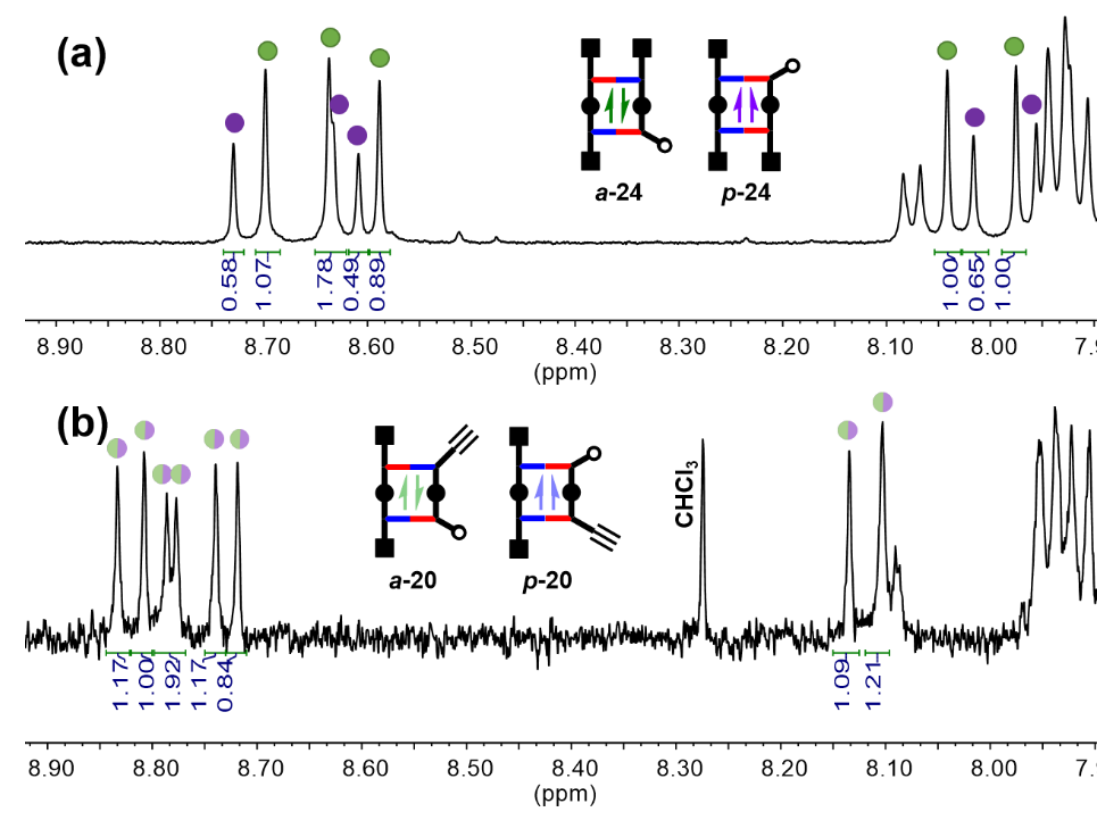

Figure S8. Triazole region of ${ }^{1} \mathrm{H}-\mathrm{NMR}\left(500 \mathrm{MHz}, \mathrm{DMSO}-\mathrm{d}_{6}\right)$ of parallel and antiparallel products 24 (a) and 20 (b). The mixture in (a) was obtained from CuAAC reaction of $19(25 \mu \mathrm{M})$ with CuTBTA $(50 \mu \mathrm{M})$ in the presence 4-t-butylbenzyl azide $(1.25 \mathrm{mM})$ in THF at room temperature. The mixture in (b) was obtained from CuAAC reaction of $19(25 \mu \mathrm{M})$ with CuTBTA $(50 \mu \mathrm{M})$ in the absence of capping agent. Triazole signals are indicated by coloured dots. Spectrum (a) was recorded at $373 \mathrm{~K}$ and spectrum (b) was recorded at $333 \mathrm{~K}$. 


\section{Hydrolysis of $a-24$.}

As shown in Scheme S1, basic hydrolysis of compound $\boldsymbol{a - 2 4}$ yields a mixture of template 16 and phenol-derived copy. A solution of $\boldsymbol{a}-\mathbf{2 4}$ in THF $(0.3 \mathrm{mM})$ was treated with $1 \mathrm{M}$ $\mathrm{LiOH}$ soln. (10 equivalents) and, after $10 \mathrm{~min}$ of stirring at $\mathrm{rt}$, the mixture was analysed by UPLC (Figure S9).

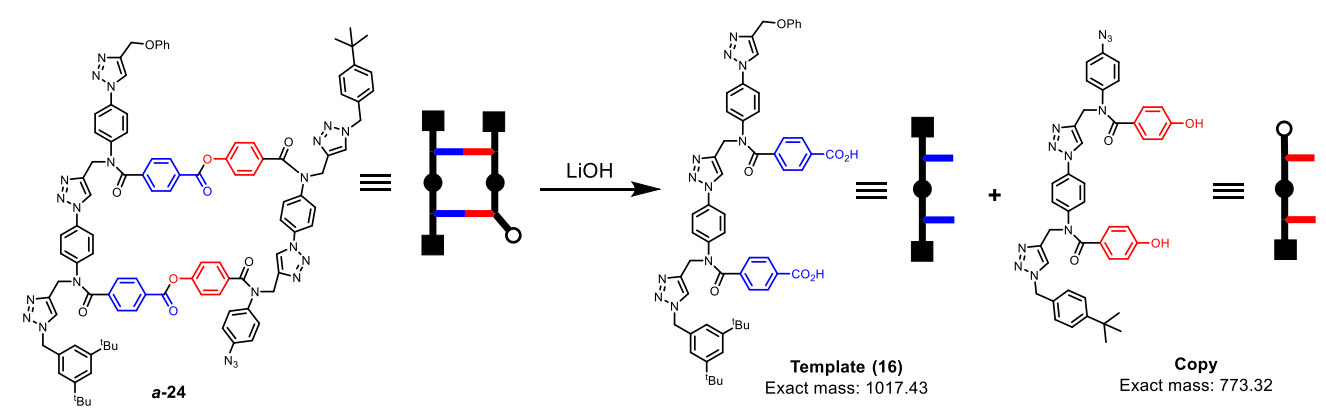

Scheme S1.
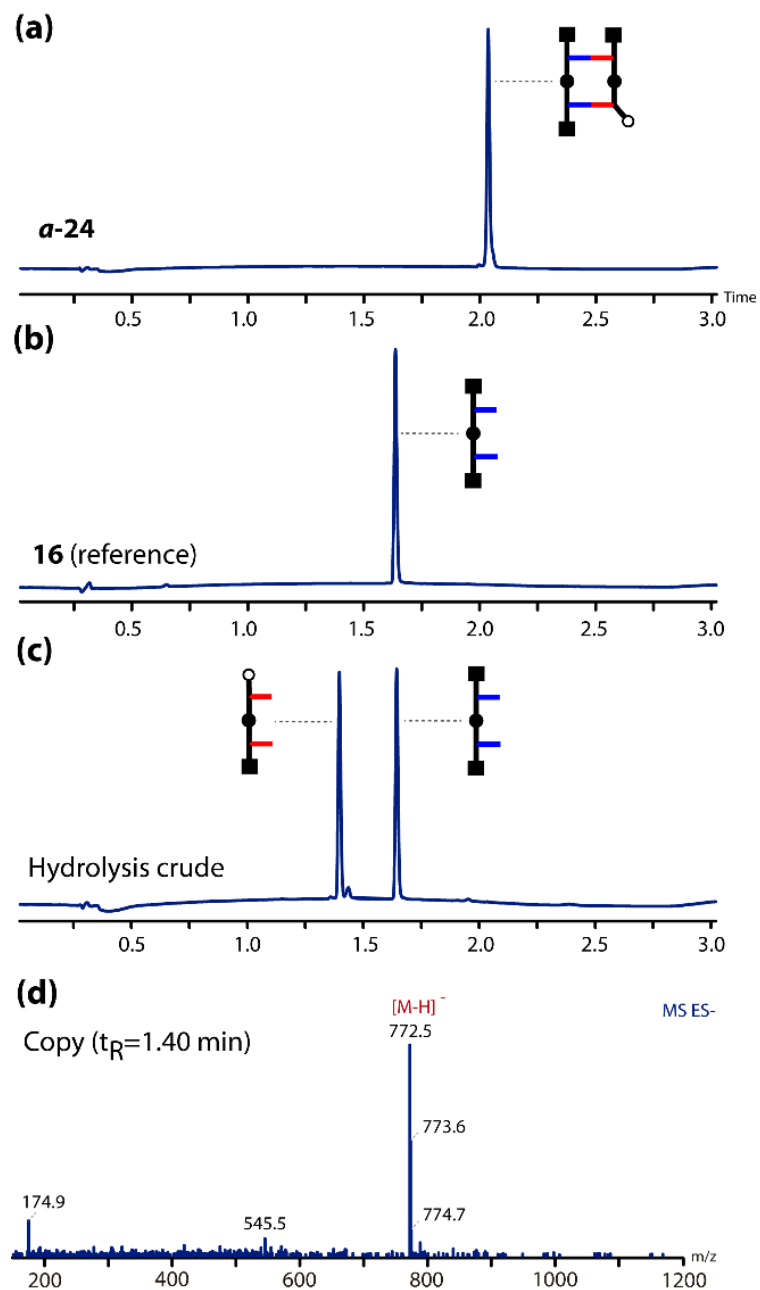

Figure S9. UPLC traces for $\boldsymbol{a - 2 4}$ (a), template $\mathbf{1 6}$ (b) as reference and the crude mixture after hydrolysis (c); Conditions: $\mathrm{C} 18$ column at $40{ }^{\circ} \mathrm{C}(254 \mathrm{~nm})$ using water $+0.1 \%$ formic acid (A) and $\mathrm{CH}_{3} \mathrm{CN}+0.1 \%$ formic acid (B) with flow rate of $0.6 \mathrm{ml} / \mathrm{min}$; Gradient of $0-3$ minutes $5 \%-95 \% \mathrm{~B}+2$ minutes $95 \% \mathrm{~B}$. Mass spectra of the peak corresponding to copy $\left(t_{R}=1.40 \mathrm{~min}\right.$ in chromatogram (c)). 


\section{Characterisations}

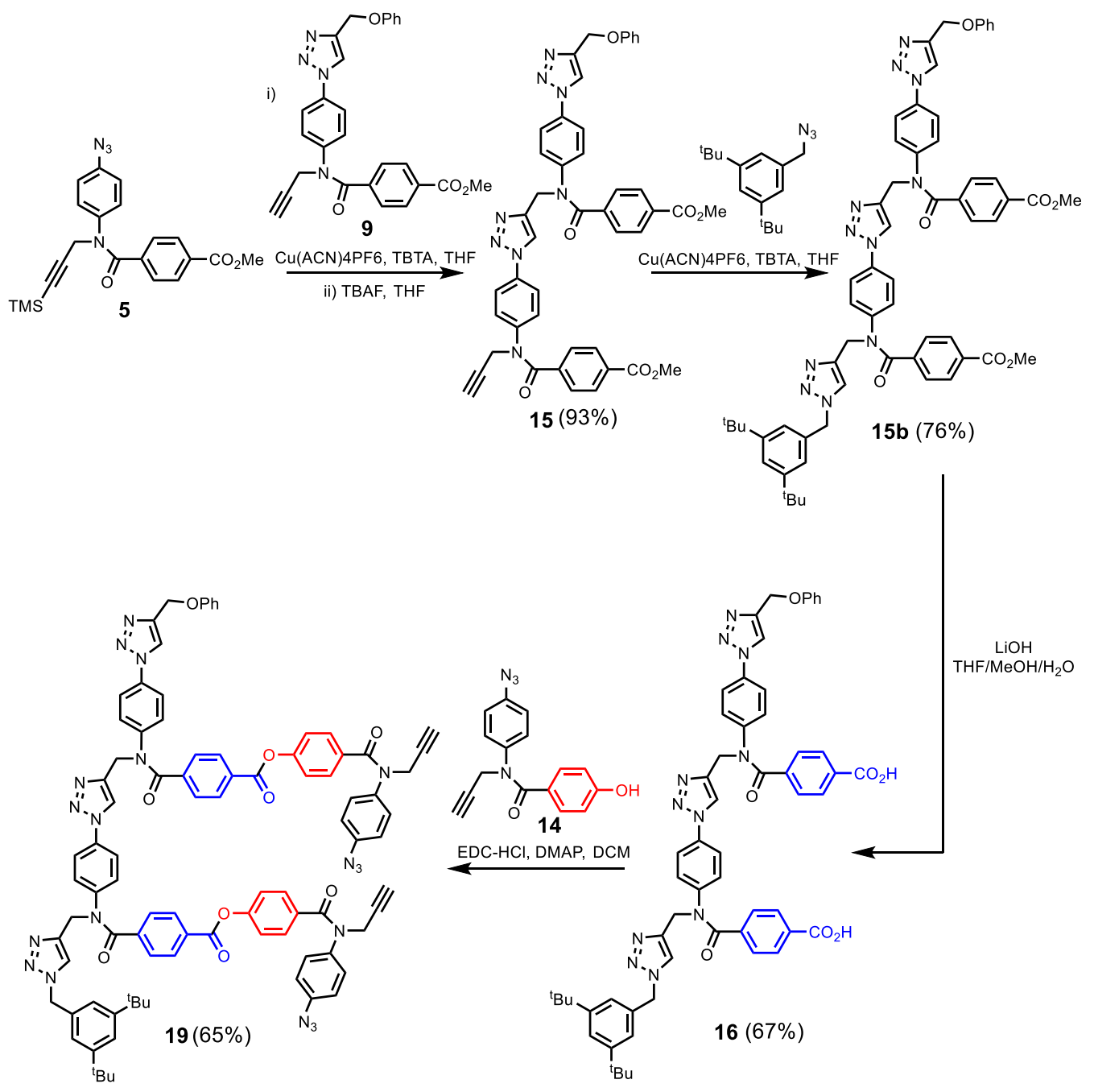

Scheme S2. Synthetic scheme of template 16 and pre-ZIP compound 19. Synthesis of compounds $\mathbf{5 , 9}$ and 14 has been previously reported. ${ }^{\mathrm{S} 1}$ 


\section{Compound 15}

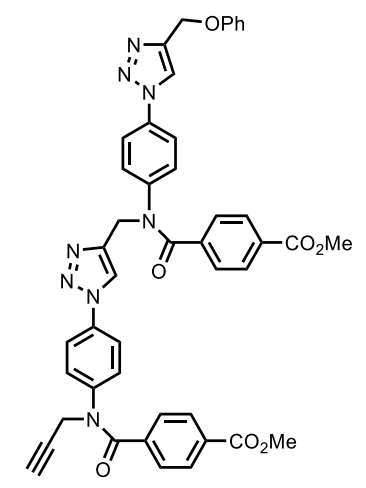

Compounds 5 (0.120 g, $0.295 \mathrm{mmol})$ and 9 (0.131 g, $0.281 \mathrm{mmol}), \mathrm{Cu}\left(\mathrm{CH}_{3} \mathrm{CN}\right)_{4} \mathrm{PF}_{6}$ $(0.010 \mathrm{~g}, 0.027 \mathrm{mmol})$ and TBTA $(0.015 \mathrm{~g}, 0.028 \mathrm{mmol})$ were mixed in a round-bottom flask and THF ( $5 \mathrm{~mL}$ ) was added under $\mathrm{N}_{2}$. The reaction was stirred overnight at room temperature. Once the reaction was completed, TBAF ( $1 \mathrm{M}$ in THF, $0.280 \mathrm{~mL}, 0.280$ mmol) was added dropwise. The solution was stirred for $10 \mathrm{~min}$ at room temperature, quenched with $0.1 \mathrm{M} \mathrm{HCl}_{(\mathrm{aq})}$ solution and extracted with EtOAc (3x) followed by washing with $\mathrm{H}_{2} \mathrm{O}(1 \mathrm{x})$ and brine $(1 \mathrm{x})$. The organic layer was dried over anhydrous $\mathrm{MgSO}_{4}$ and concentrated under vacuum. The crude was purified by flash column chromatography on silica gel (gradient from 10\% to 80\% of EtOAc in Pet. Ether) to afford 15 (0.204 g, 93\%) as a foam.

${ }^{1}$ H NMR (400 MHz, CDCl 3$): \delta_{\mathrm{H}}=8.19(\mathrm{~s}, 1 \mathrm{H}), 7.98(\mathrm{~s}, 1 \mathrm{H}), 7.88(\mathrm{~d}, 2 \mathrm{H}, J=8.5 \mathrm{~Hz})$, $7.85(\mathrm{~d}, 2 \mathrm{H}, J=8.5 \mathrm{~Hz}), 7.68(\mathrm{~d}, 2 \mathrm{H}, J=9.0 \mathrm{~Hz}), 7.62(\mathrm{~d}, 2 \mathrm{H}, J=9.0 \mathrm{~Hz}), 7.42(\mathrm{~d}, 2 \mathrm{H}$, $J=8.5 \mathrm{~Hz}), 7.36-7.29(\mathrm{~m}, 8 \mathrm{H}), 6.99(\mathrm{~m}, 3 \mathrm{H}), 5.28(\mathrm{~s}, 2 \mathrm{H}), 5.21(\mathrm{~s}, 2 \mathrm{H}), 4.72(\mathrm{~d}, 2 \mathrm{H}, J=$ $2.5 \mathrm{~Hz}), 3.86$ (s, 3H), 3.86 (s, 3H), 2.30 (t, $1 \mathrm{H}, J=2.5 \mathrm{~Hz})$.

${ }^{13}$ C NMR (100.6 MHz, CDCl3): $\delta_{\mathrm{C}}=169.5,169.3,166.2,166.2,158.2,145.5,144.5$, $143.9,142.6,139.2,139.1,135.8,135.5,131.8,131.7,129.8,129.5,129.5,129.2,128.8$, $128.8,122.2$, 121.6, 121.5, 121.2, 120.8, 114.9, 78.4, 73.3, 62.0, 52.5, 52.5, 46.4, 39.8.

HRMS (ES+): calcd for $\mathrm{C}_{45} \mathrm{H}_{37} \mathrm{~N}_{8} \mathrm{O}_{7} 801.2785[\mathrm{M}+\mathrm{H}]^{+}$, found $801.2778[\mathrm{M}+\mathrm{H}]^{+}$. FT-IR (ATR): $v_{\max }$ 2951, 1720, 1650, 1519, 1279, 1240, 1109, 755 and $732 \mathrm{~cm}^{-1}$. 
${ }^{1}$ H-NMR (400 MHz, CDCl 3 ) Compound 15.

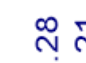

ing 2

$\begin{array}{lll}0 & 0 \\ \infty & \infty \\ \infty & \infty\end{array}$

min

్ㅏㅇㅛ 요

n n N

$\checkmark$
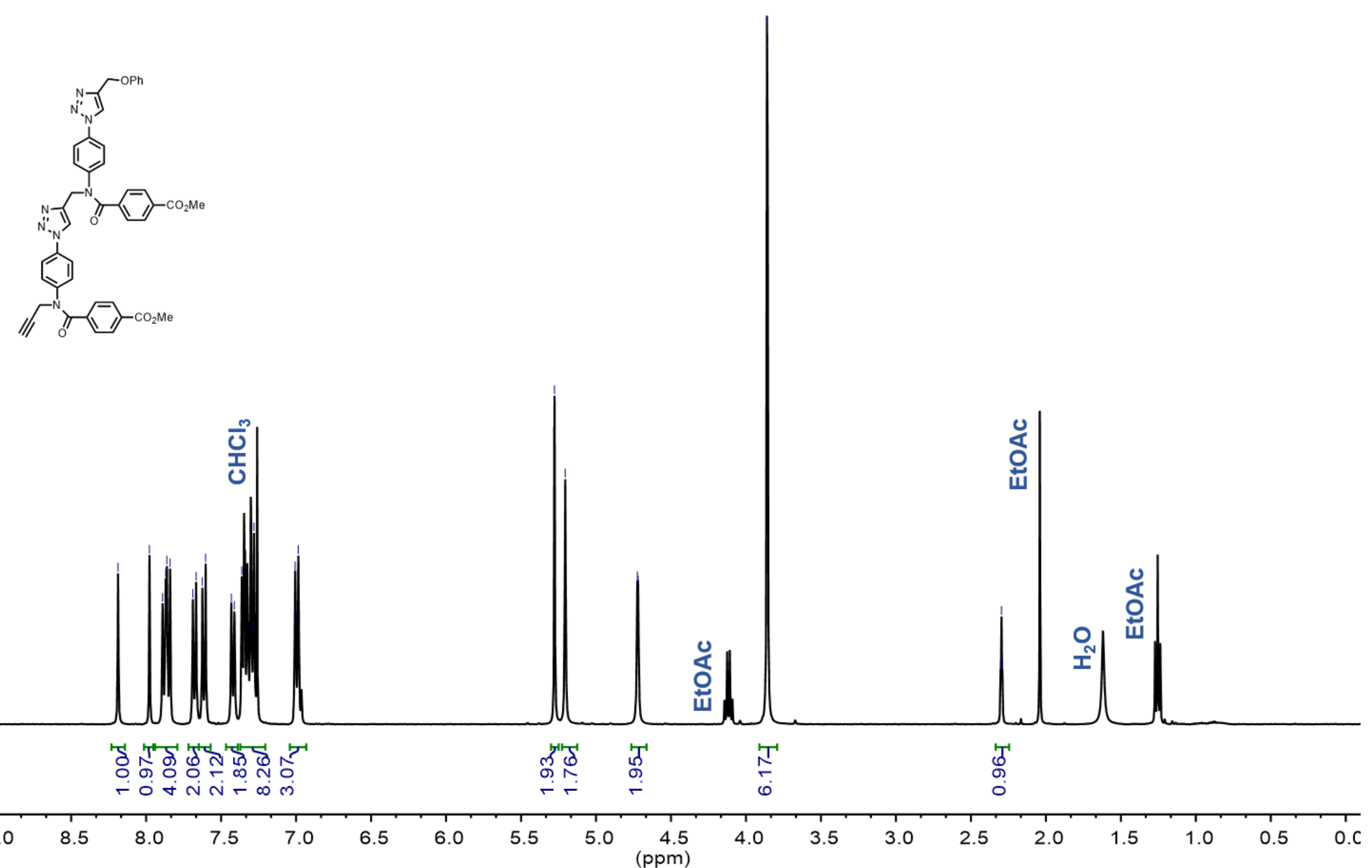

9.0

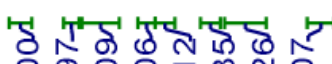
-0
0

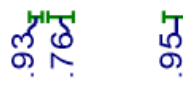


${ }^{13} \mathrm{C}-\mathrm{NMR}$ (100.6 MHz, $\mathrm{CDCl}_{3}$ ) Compound 15.

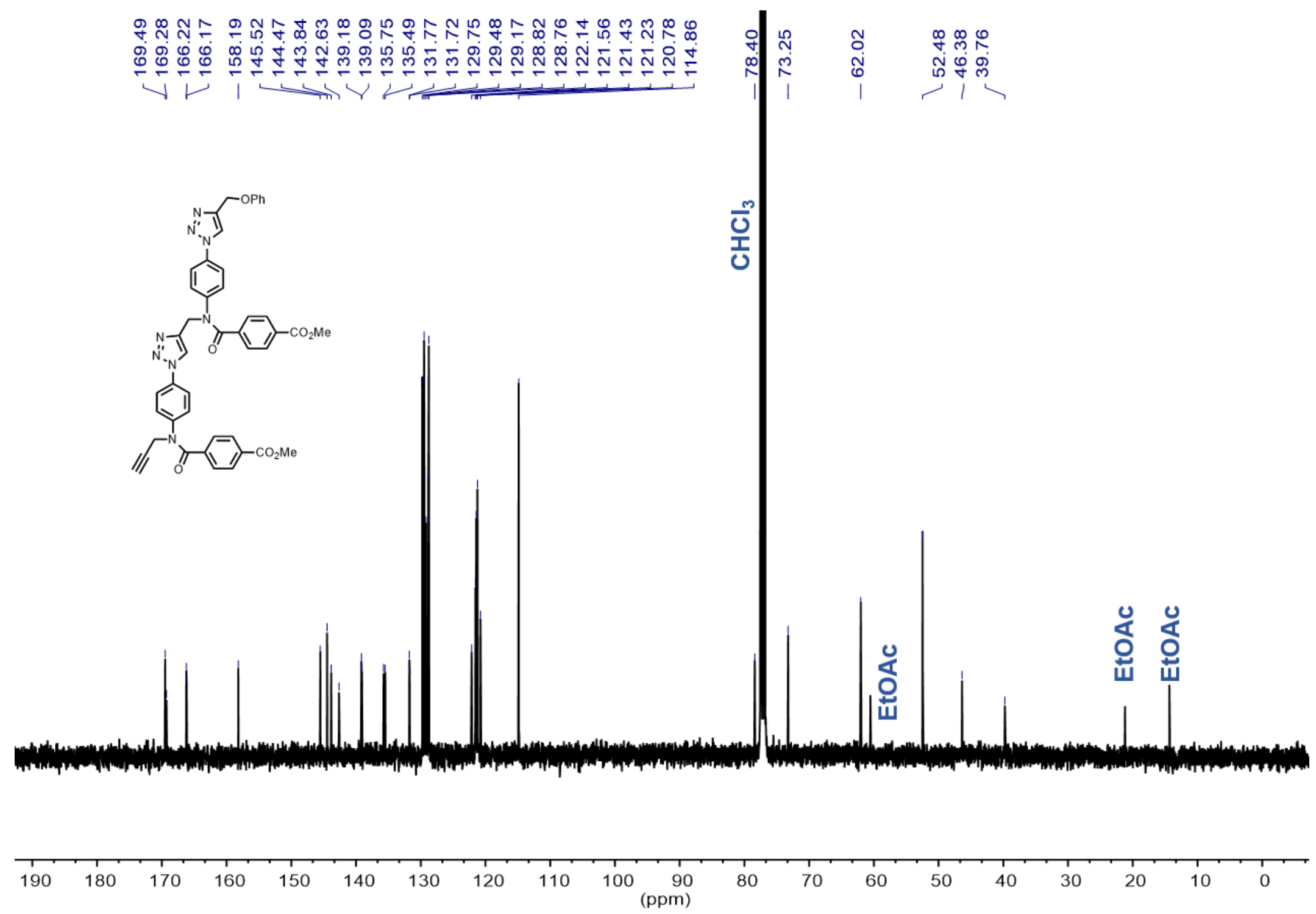




\section{Compound 15b}

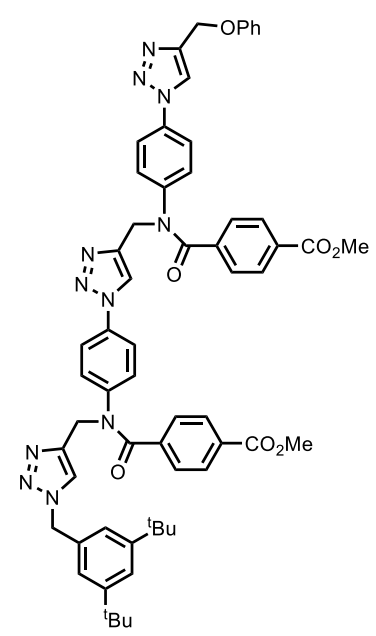

$0.460 \mathrm{~g}(0.574 \mathrm{mmol})$ of 15 and $0.282 \mathrm{~g}(1.15 \mathrm{mmol})$ of 1-(azidomethyl)-3,5-di-tertbutylbenzene were dissolved in $10 \mathrm{~mL}$ of dry THF and then $0.015 \mathrm{~g}(0.028 \mathrm{mmol})$ of TBTA and $0.011 \mathrm{~g}(0.030 \mathrm{mmol})$ of $\mathrm{Cu}\left(\mathrm{CH}_{3} \mathrm{CN}\right)_{4} \mathrm{PF}_{6}$ were added. The mixture was stirred at room temperature under nitrogen overnight, then the solvent was evaporated and the crude was purified on a $4 \mathrm{~g}$ silica column (0 to $80 \%$ gradient of EtOAc in Pet. Ether). $0.465 \mathrm{~g}$ (76\%) of pure product were isolated as a colourless oil.

${ }^{1}$ H NMR (400 MHz, CDCl $)$ : $\delta_{\mathrm{H}}=8.16(\mathrm{~s}, 1 \mathrm{H}), 7.98(\mathrm{~s}, 1 \mathrm{H}), 7.87-7.83(\mathrm{~m}, 4 \mathrm{H}), 7.70(\mathrm{~s}, 1 \mathrm{H})$, 7.63-7.60 (m, 4H), 7.40-7.29 (m, 12H), 7.07 (d, 2H, J = 1.0 Hz), 7.01-6.97 (m, 3H), $5.51(\mathrm{~s}$, $2 \mathrm{H}), 5.28(\mathrm{~s}, 2 \mathrm{H}), 5.21(\mathrm{~s}, 2 \mathrm{H}), 5.14(\mathrm{~s}, 2 \mathrm{H}), 3.86(\mathrm{~s}, 3 \mathrm{H}), 3.85(\mathrm{~s}, 3 \mathrm{H}), 1.28(\mathrm{~s}, 18 \mathrm{H})$.

${ }^{13}$ C NMR (125.7 MHz, CDCl3): $\delta_{C}=169.5,169.4,166.2,166.2,158.2,151.9,145.5,144.4$, $143.8,143.8,139.4,139.2$, 135.5, 135.3, 133.8, 131.7, 131.6, 129.8, 129.5, 129.4, 128.8, 128.8, 124.0, 123.0, 122.4, 122.1, 121.6, 121.4, 121.2, 120.8, 114.9, 62.0, 55.0, 52.5, 46.4, 46.3, 35.0, 31.5, 24.0.

HRMS (ES+): calcd for $\mathrm{C}_{60} \mathrm{H}_{60} \mathrm{O}_{7} \mathrm{~N}_{11} 1046.4672[\mathrm{M}+\mathrm{H}]^{+}$, found $1046.4663[\mathrm{M}+\mathrm{H}]^{+}$.

FT-IR (ATR): $v_{\max } 2953,1721,1645,1517,1274,1234,1107,1042$. 
${ }^{1} \mathrm{H}-\mathrm{NMR}$ (500 MHz, CDCl ) Compound 15b.

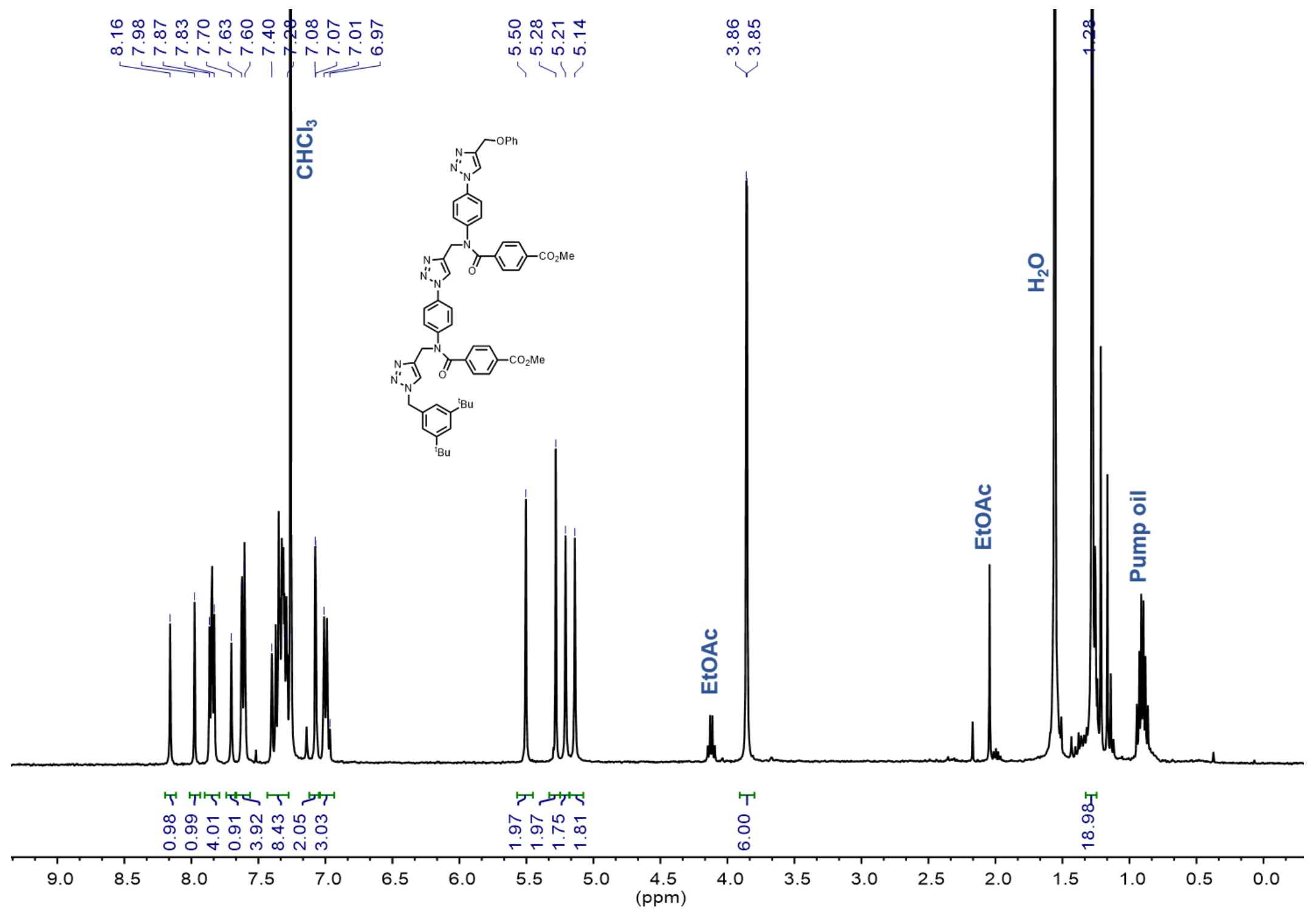


${ }^{13} \mathrm{C}$ NMR (125.7 MHz, $\left.\mathrm{CDCl}_{3}\right)$ Compound $15 \mathrm{~b}$.

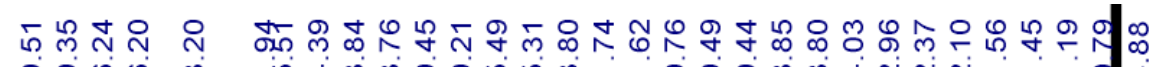

V

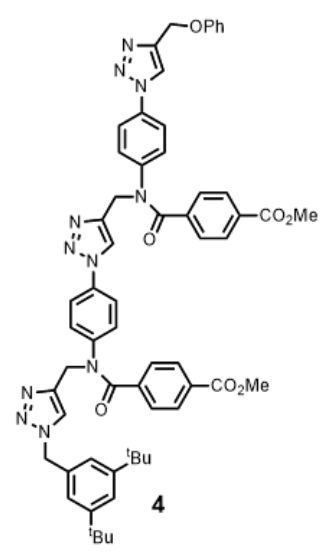

ํㅗㄴ

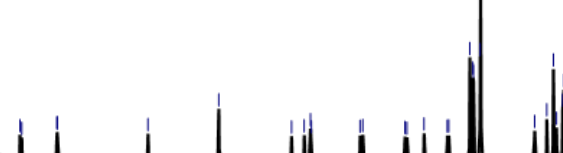

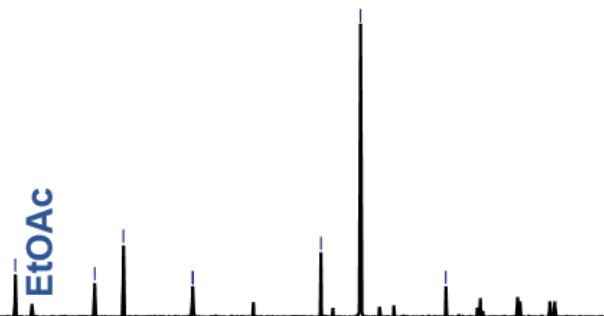

180170

160

150

140

$30 \quad 120$

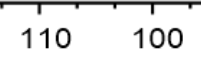




\section{Compound 16}

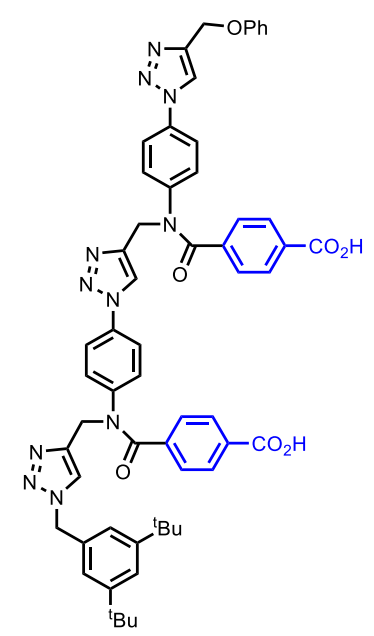

$0.450 \mathrm{~g}(0.430 \mathrm{mmol})$ of $\mathbf{1 5 b}$ were dissolved in $4.5 \mathrm{~mL}$ of $\mathrm{THF} / \mathrm{MeOH} / \mathrm{H}_{2} \mathrm{O}(2.5: 1: 1 \mathrm{v} / \mathrm{v})$ and then lithium hydroxide $(0.090 \mathrm{~g}, 2.2 \mathrm{mmol})$ was added. The reaction was monitored by LC-MS until disappearance of the signal of the starting material (ca. $2 \mathrm{~h}$ ) and then it was quenched by adding $3 \mathrm{ml}$ of $1 \mathrm{M} \mathrm{HCl}_{(\mathrm{aq})}$. The mixture was extracted with EtOAc (3x) and the combined organic phase was dried over $\mathrm{MgSO}_{4}$ and evaporated under reduced pressure. The crude was purified on silica column ( 0 to $8 \%$ gradient of $\mathrm{MeOH}$ containing $10 \%$ acetic acid in $\mathrm{CH}_{2} \mathrm{Cl}_{2}$ ). $0.300 \mathrm{~g}(67 \%)$ of the pure compound were isolated as a white wax.

${ }^{1}$ H NMR (500 MHz, CDCl $): \delta_{\mathrm{H}}=8.21(\mathrm{~s}, 1 \mathrm{H}), 7.97(\mathrm{~s}, 1 \mathrm{H}), 7.88-7.85(\mathrm{~m}, 4 \mathrm{H}), 7.72(\mathrm{~s}, 1 \mathrm{H})$, 7.64-7.60 (m, 4H), $7.40(\mathrm{t}, 1 \mathrm{H}, \mathrm{J}=1.5 \mathrm{~Hz}), 7.35-7.26(\mathrm{~m}, 10 \mathrm{H}), 7.08(\mathrm{~d}, 2 \mathrm{H}, \mathrm{J}=1.5 \mathrm{~Hz})$, 7.00-6.96 (m, 3H), $5.51(\mathrm{~s}, 2 \mathrm{H}), 5.28(\mathrm{~s}, 2 \mathrm{H}), 5.20(\mathrm{~s}, 2 \mathrm{H}), 5.15(\mathrm{~s}, 2 \mathrm{H}), 1.28(\mathrm{~s}, 18 \mathrm{H})$.

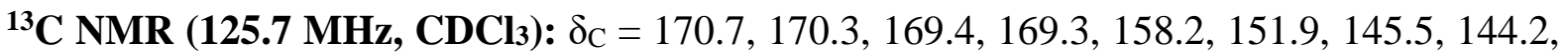
$143.8,143.7,140.2,139.8,135.5,135.4,133.8,131.0,130.8,130.0,129.8,128.9,128.8,124.1$, 123.0, 122.4, 122.2, 121.6, 121.5, 121.1, 120.9, 114.9, 62.0, 55.0, 46.4, 46.2, 35.0, 31.5.

HRMS (ES+): calcd for $\mathrm{C}_{58} \mathrm{H}_{56} \mathrm{O}_{7} \mathrm{~N}_{11} 1018.4359[\mathrm{M}+\mathrm{H}]^{+}$, found $1018.4345[\mathrm{M}+\mathrm{H}]^{+}$.

FT-IR (ATR): $v_{\max }$ 2955, 1714, 1645, 1517, 1229, 1042. 
${ }^{1}$ H-NMR (500 MHz, CDCl3) Compound 16.

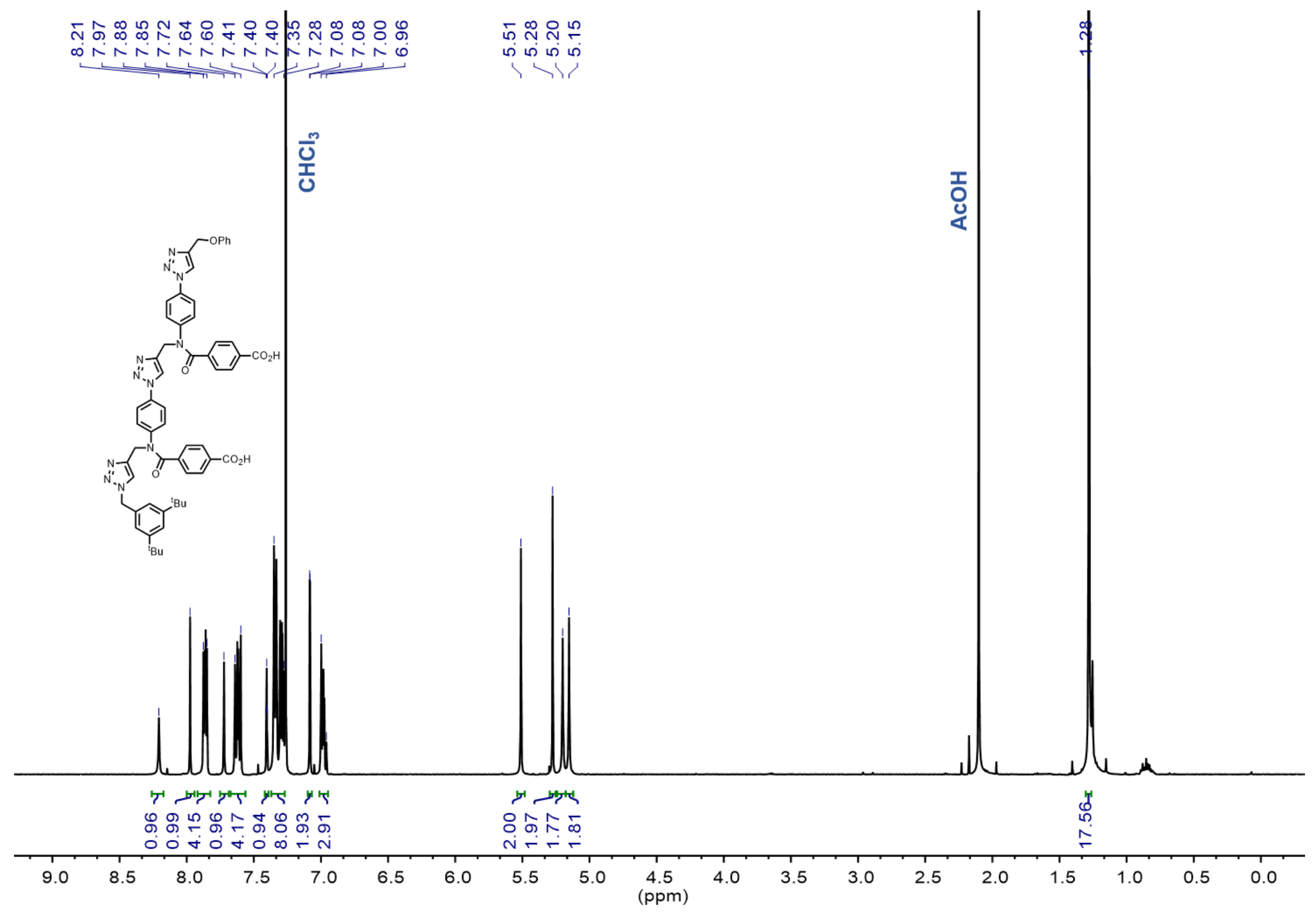


${ }^{13} \mathrm{C}$ NMR (125.7 MHz, CDCl 3 ) Compound 16.
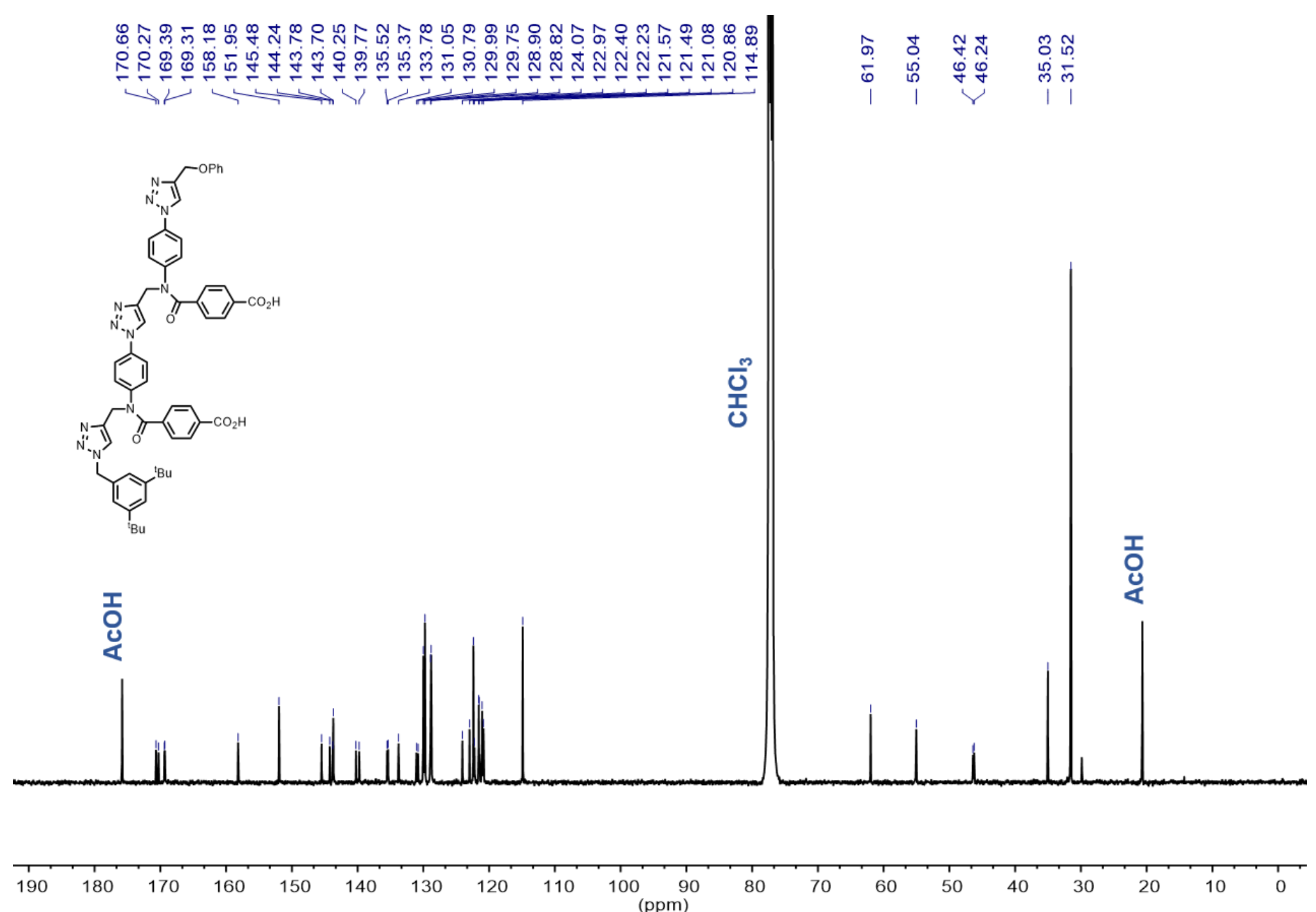


\section{Compound 19}

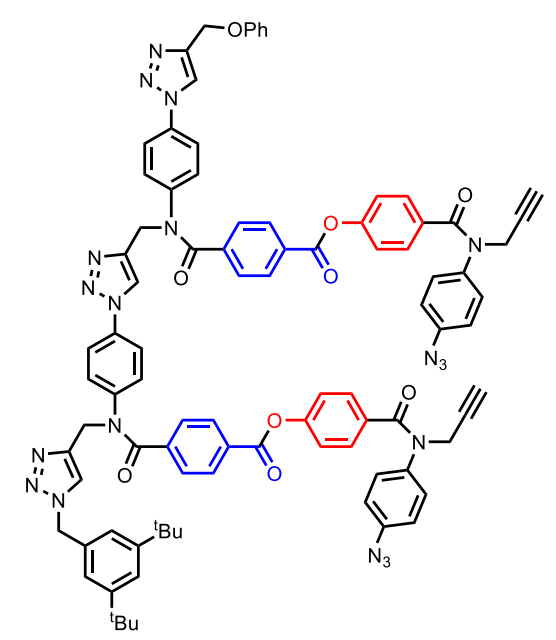

To a flask containing $5 \mathrm{~mL}$ of dry $\mathrm{CH}_{2} \mathrm{Cl}_{2}$ were added under nitrogen $0.071 \mathrm{~g}(0.25 \mathrm{mmol})$ of compound 14, $0.100 \mathrm{~g}(0.0982 \mathrm{mmol})$ of 16, $0.041 \mathrm{~g}(0.22 \mathrm{mmol})$ of EDC- $\mathrm{HCl}$ and $0.003 \mathrm{~g}$ (0.02 mmol) of DMAP. The mixture was stirred at room temperature overnight, then diluted with $5 \mathrm{~mL}$ of $\mathrm{CH}_{2} \mathrm{Cl}_{2}$ and washed with $1 \mathrm{M} \mathrm{HCl}_{(\mathrm{aq})}(2 \mathrm{x})$ and of brine (1x). The organic solvent was dried over $\mathrm{MgSO}_{4}$ and evaporated under reduced pressure. The crude was purified on silica column (first with a gradient of 0 to $80 \%$ EtOAc in Pet. Ether and then with a gradient of 0 to $3 \% \mathrm{MeOH}$ in $\left.\mathrm{CH}_{2} \mathrm{Cl}_{2}\right) .0 .100 \mathrm{~g}(65 \%)$ of the pure compound were isolated as a pale-yellow wax.

${ }^{1} \mathbf{H}$ NMR (400 MHz, CDCl $): \delta_{\mathrm{H}}=8.17(\mathrm{~s}, 1 \mathrm{H}), 7.99(\mathrm{~s}, 1 \mathrm{H}), 7.97-7.94(\mathrm{~m}, 4 \mathrm{H}), 7.71(\mathrm{~s}, 1 \mathrm{H})$, 7.65-7.62 (m, 4H), 7.42-7.26 (m, 12H), 7.14-7.11 (m, 4H), $7.08(\mathrm{~d}, 2 \mathrm{H}, \mathrm{J}=1.5 \mathrm{~Hz}), 7.04-6.97$ $(\mathrm{m}, 6 \mathrm{H}), 6.93-6.90(\mathrm{~m}, 4 \mathrm{H}), 5.51$ (s. $2 \mathrm{H}), 5.28(\mathrm{~s}, 2 \mathrm{H}), 5.21(\mathrm{~s}, 2 \mathrm{H}), 5.15(\mathrm{~s}, 2 \mathrm{H}), 4.65-4.63(\mathrm{~m}$, $4 \mathrm{H}), 2.25(\mathrm{t}, 2 \mathrm{H}, \mathrm{J}=2 \mathrm{~Hz}), 1.28(\mathrm{~s}, 18 \mathrm{H})$.

${ }^{13}$ C NMR (125.7 MHz, CDCl3): $\delta_{\mathrm{C}}=169.3,169.2,169.1,163.7,163.7,158.2,152.0,145.6$, 144.4, 143.7, 140.3, 140.1, 139.5, 139.4, 135.6, 135.4, 133.8, 132.7, 130.7, 130.6, 130.1, 130.0, $129.8,129.3,129.0,129.0,128.9,124.0,123.0,122.4,122.2,121.6,121.5,121.3,121.2,120.8$, $120.0,114.9,78.8,72.8,68.1,62.0,55.0,46.4,40.1,35.0,31.5$.

HRMS (ES+): calcd for $\mathrm{C}_{90} \mathrm{H}_{76} \mathrm{O}_{9} \mathrm{~N}_{19} 1566.6068[\mathrm{M}+\mathrm{H}]^{+}$, found $1566.6133[\mathrm{M}+\mathrm{H}]^{+}$.

FT-IR (ATR): $v_{\max }$ 3291, 3061, 2956, 2863, 2121, 2092, 1739, 1644, 1504, 1375, 1258, 1199 , 1066. 
${ }^{1}$ H-NMR (400 MHz, CDCl3) Compound 19.

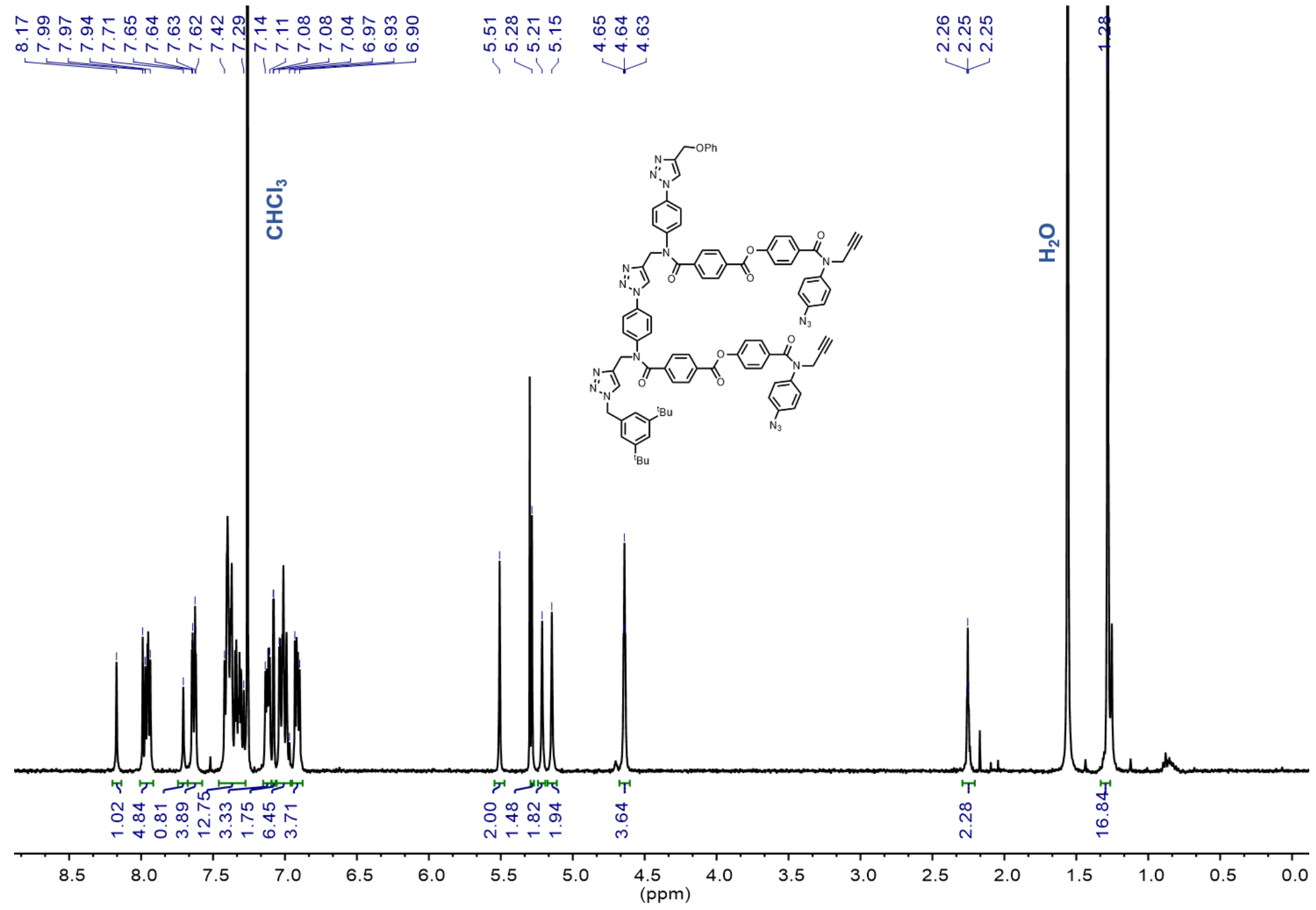


${ }^{13} \mathrm{C}$ NMR (100.6 MHz, CDCl 3 ) Compound 19.
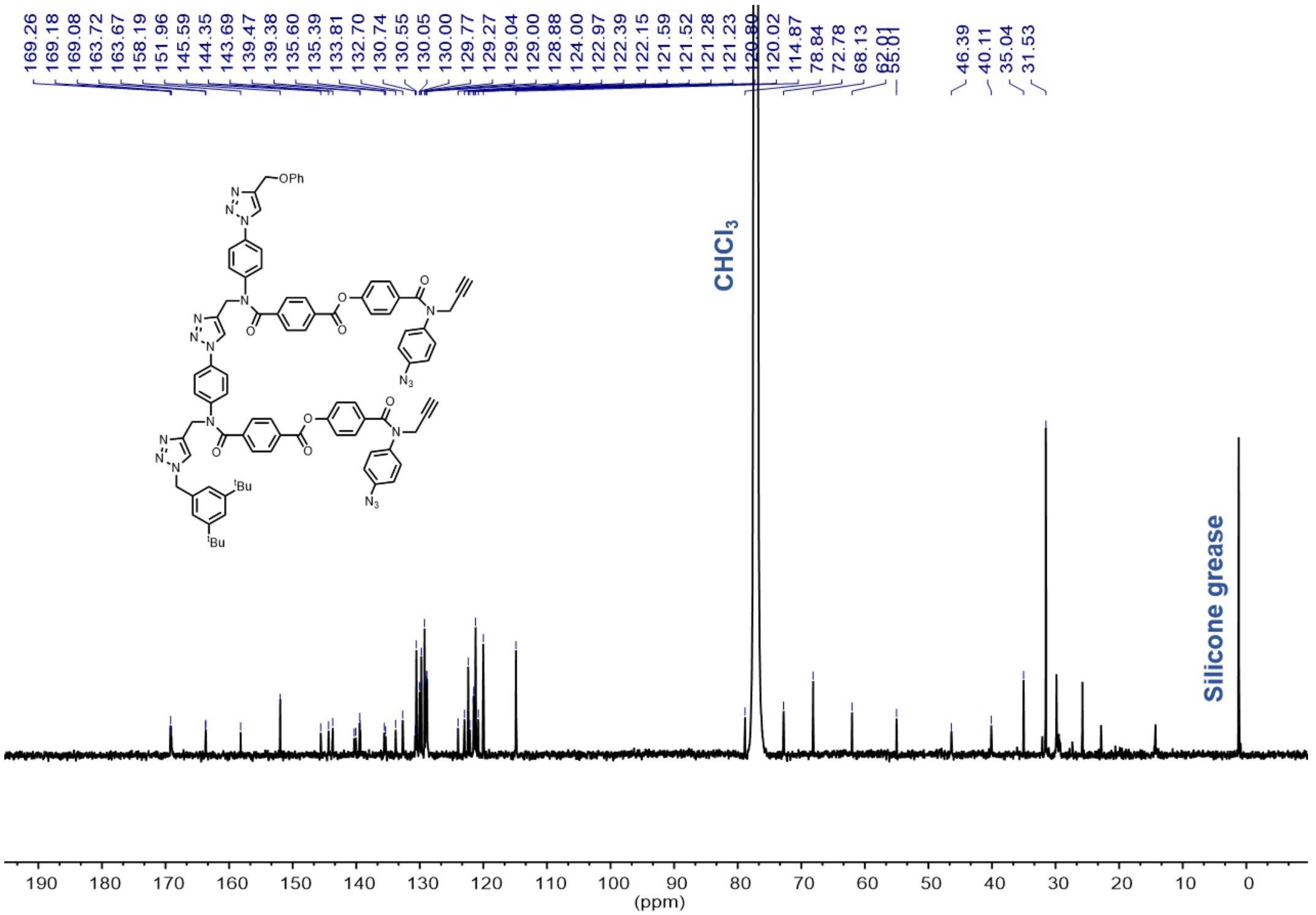


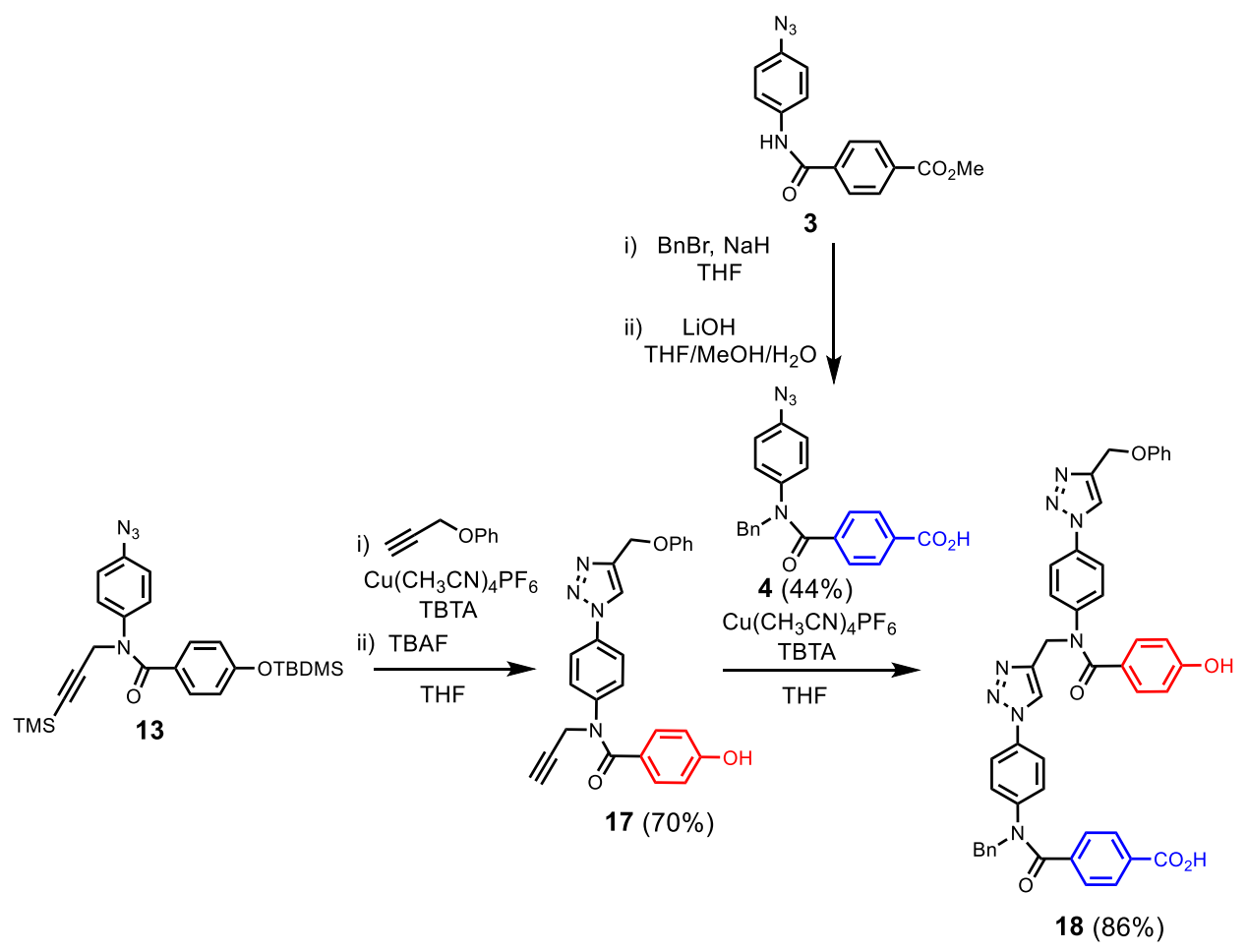

Scheme S-3. Synthetic scheme of 18. Synthesis of compounds 3 and $\mathbf{1 3}$ is described in reference 1. 


\section{Compound 17}

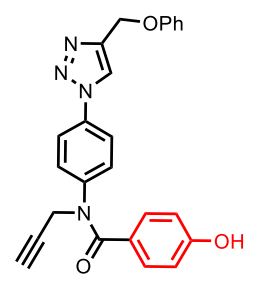

Compound $13(0.320 \mathrm{~g}, 0.668 \mathrm{mmol}), \mathrm{Cu}\left(\mathrm{CH}_{3} \mathrm{CN}\right)_{4} \mathrm{PF}_{6}(0.025 \mathrm{~g}, 0.067 \mathrm{mmol})$ and TBTA $(0.036 \mathrm{~g}, 0.067 \mathrm{mmol})$ were mixed in a round-bottom flask and THF $(5 \mathrm{~mL})$ was added under $\mathrm{N}_{2}$. Phenyl propargyl ether $(0.170 \mathrm{~mL}, 1.34 \mathrm{mmol})$ was added and the reaction was stirred overnight at room temperature. Once the reaction was completed, TBAF (1M in THF, $1.34 \mathrm{~mL}, 1.34 \mathrm{mmol}$ ) was added dropwise. The solution was stirred for $10 \mathrm{~min}$ at room temperature, quenched with $5 \% . \mathrm{HCl}_{(\mathrm{aq})}$ solution and extracted with EtOAc $(3 \mathrm{x})$ followed by washing with $\mathrm{H}_{2} \mathrm{O}(1 \mathrm{x})$ and brine (1x). The organic layer was dried over anhydrous $\mathrm{MgSO}_{4}$ and concentrate under vacuum. The crude was purified by flash column chromatography on silica gel (gradient from $0 \%$ to $50 \%$ of EtOAc in Pet. Ether) to afford $17(0.229 \mathrm{~g}, 81 \%)$ as a foam.

${ }^{1}$ H NMR (400 MHz, CDCl 3$): \delta_{\mathrm{H}}=8.46(\mathrm{~s}, 1 \mathrm{H}), 8.03(\mathrm{~s}, 1 \mathrm{H}), 7.62(\mathrm{~d}, 2 \mathrm{H}, J=9.0 \mathrm{~Hz})$, $7.27(\mathrm{~m}, 4 \mathrm{H}), 7.20(\mathrm{~d}, 2 \mathrm{H}, J=8.5 \mathrm{~Hz}), 6.97$ (t partially overlapped, $J=7.0 \mathrm{~Hz}), 6.96(\mathrm{~d}$, $2 \mathrm{H}, J=8.5 \mathrm{~Hz}), 6.64(\mathrm{~d}, 2 \mathrm{H} J=8.5 \mathrm{~Hz}), 5.23(\mathrm{~s}, 2 \mathrm{H}), 4.66(\mathrm{~d}, 2 \mathrm{H}, J=2.5 \mathrm{~Hz}), 2.25(\mathrm{t}$, $1 \mathrm{H}, J=2.5 \mathrm{~Hz})$.

${ }^{13}$ C NMR (100.6 MHz, CDCl3): $\delta_{\mathrm{C}}=170.6,159.2,158.1,145.3,143.8,135.1,131.3$, $129.7,128.9,125.4,121.6,121.4,121.2,115.3,114.8,78.7,73.0,61.7,40.1$.

HRMS (ES+): calcd for $\mathrm{C}_{25} \mathrm{H}_{21} \mathrm{~N}_{4} \mathrm{O}_{3} 425.1614[\mathrm{M}+\mathrm{H}]^{+}$, found $425.1597[\mathrm{M}+\mathrm{H}]^{+}$.

FT-IR (ATR): $v_{\max } 3286,1634,1604,1518,1280,1234,846$ and $756 \mathrm{~cm}^{-1}$. 
${ }^{1}$ H-NMR (400 MHz, CDCl3) Compound 17.

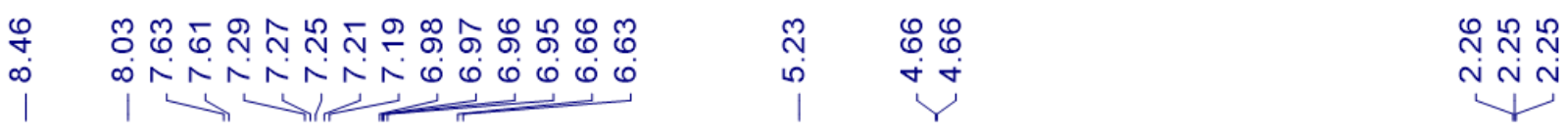
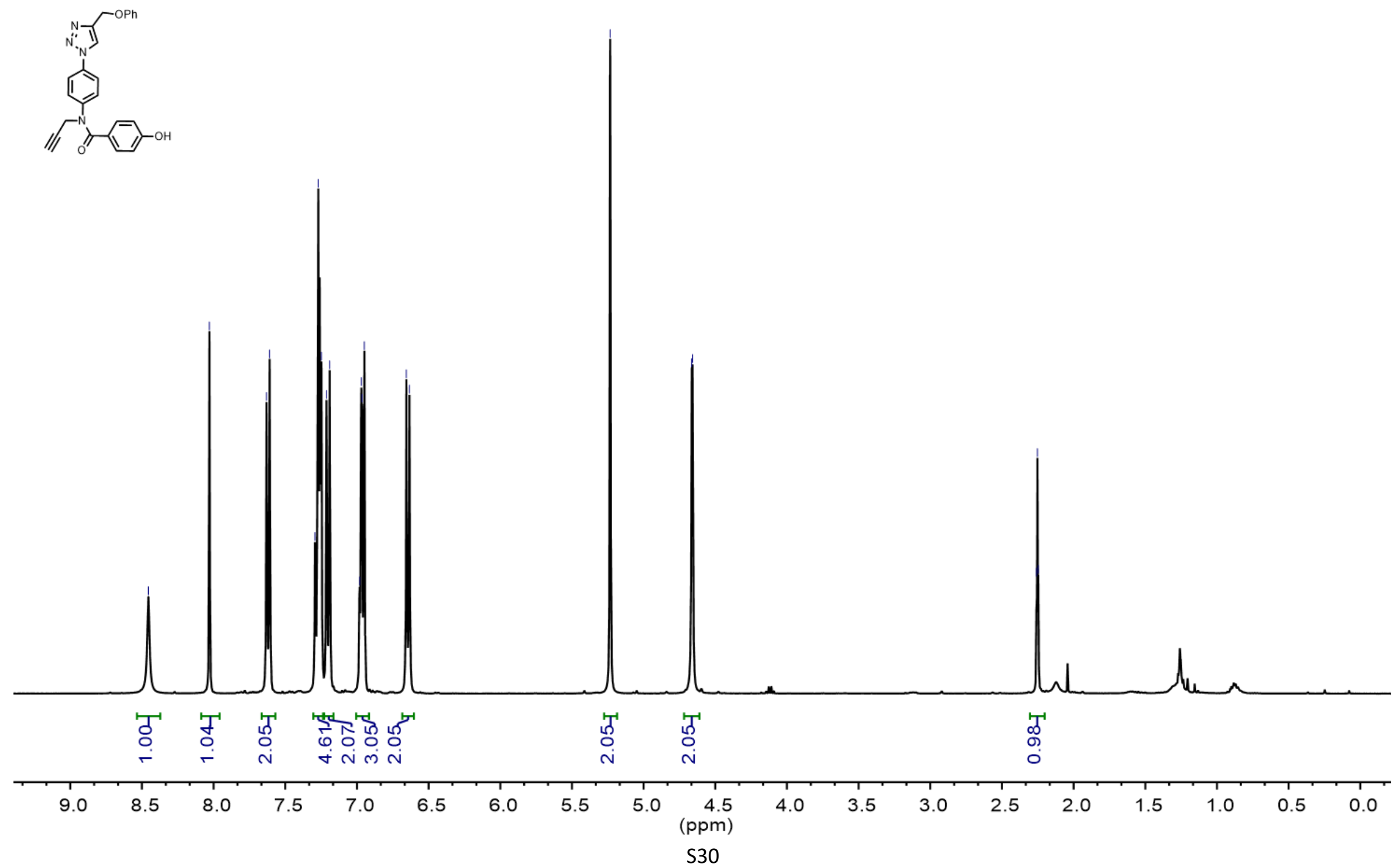
${ }^{13} \mathrm{C}-\mathrm{NMR}$ (100.6 MHz, CDCl ) Compound 17.

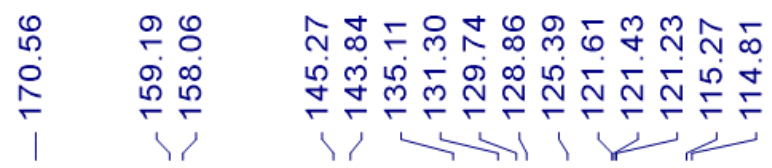

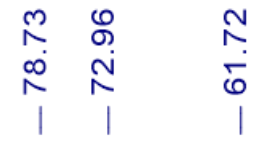

$\frac{d}{\dot{d}}$
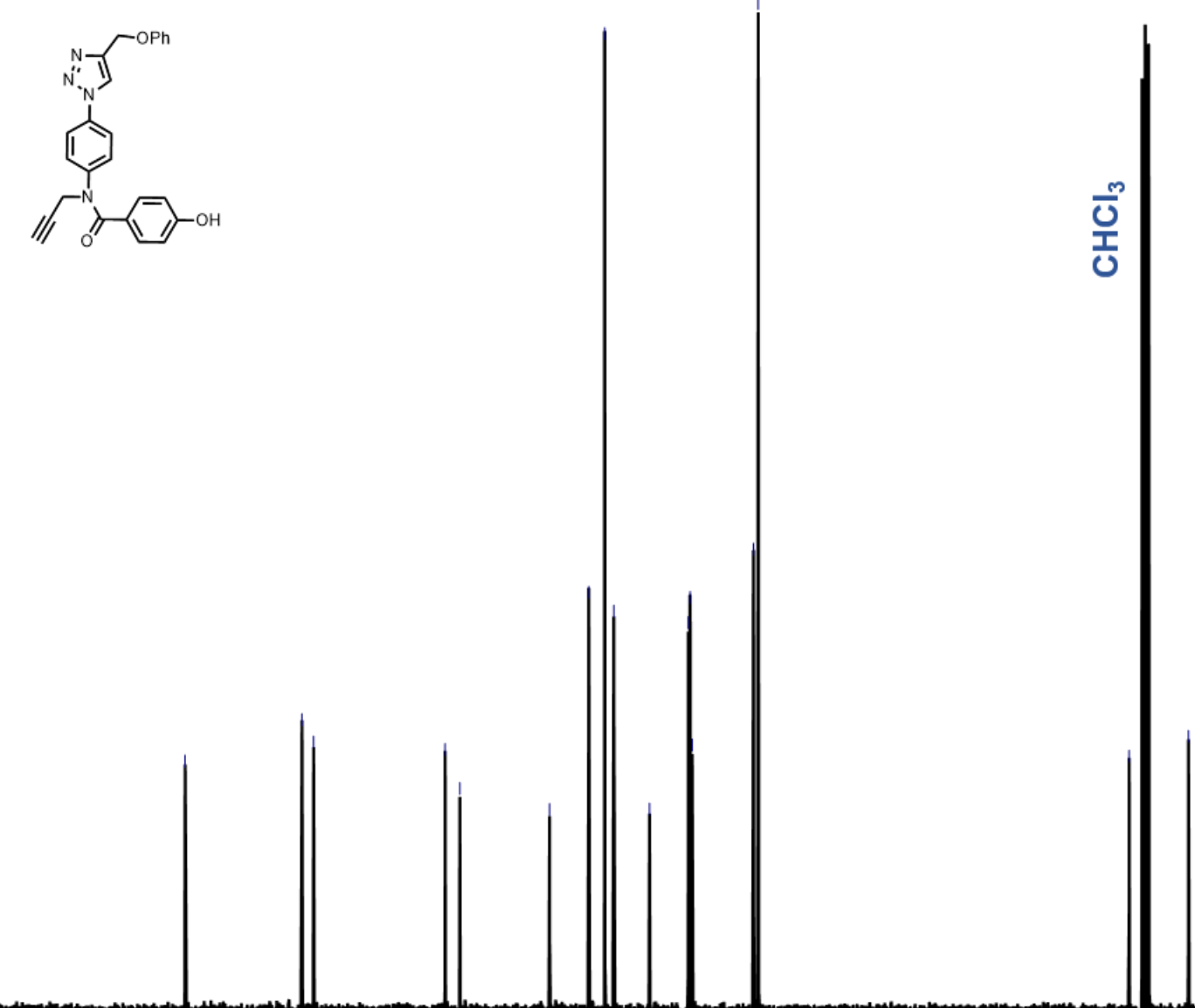

$90 \quad 180 \quad 170$ 160 150 140 130 120 


\section{Compound 4}

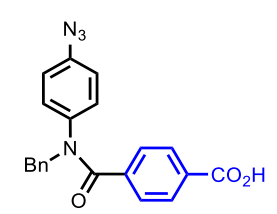

3 (0.308 g, $1.04 \mathrm{mmol}$ ) was dissolved in dry THF (3 mL) and added to a suspension of $\mathrm{NaH}$ (60\% dispersion in mineral oil, $0.125 \mathrm{~g}, 3.12 \mathrm{mmol})$ in $\mathrm{THF}(7 \mathrm{~mL})$ under inert atmosphere at $0{ }^{\circ} \mathrm{C}$. The reaction was allowed to reach room temperature for $15 \mathrm{~min}$. Benzyl bromide $(0.370 \mathrm{~mL}, 3.12 \mathrm{mmol})$ was added dropwise and the reaction was vigorously stirred overnight. Saturated aqueous. $\mathrm{NH}_{4} \mathrm{Cl}$ was carefully added at $0{ }^{\circ} \mathrm{C}$ and the reaction was extracted with EtOAc $(3 \mathrm{x})$. The combined organic phase was washed with brine $(1 \mathrm{x})$, dried with anhydrous $\mathrm{MgSO}_{4}$, filtered, and the solvents evaporated. The obtained residue was dissolved in THF/MeOH/ $\mathrm{H}_{2} \mathrm{O}(2.5: 1: 1 \mathrm{v} / \mathrm{v} / \mathrm{v})$ and $\mathrm{LiOH}(0.062 \mathrm{~g}$, $1.5 \mathrm{mmol}$ ) was added. The reaction was stirred at room temperature for $4 \mathrm{~h}$, then the crude was diluted with $\mathrm{H}_{2} \mathrm{O}$ and acidified to $\mathrm{pH}$ 2-3 with $1 \mathrm{M} \mathrm{HCl}_{(\mathrm{aq})}$ solution. The aqueous phase was extracted with EtOAc (3x) and the combined organic phase was washed with brine, dried over $\mathrm{MgSO}_{4}$ and evaporated to dryness. The obtained residue was purified by flash chromatography (from $0 \%$ to $50 \%$ of EtOAc in Pet. Ether) to afford 4 (0.171 g, $44 \%$ ) as a yellow solid.

Melting point: $154-156{ }^{\circ} \mathrm{C}$.

${ }^{1}$ H NMR (400 MHz, CDCl3): $\delta_{\mathrm{H}}=10.54(\mathrm{bs}, 1 \mathrm{H}), 7.93(\mathrm{~d}, 2 \mathrm{H}, J=7.5 \mathrm{~Hz}), 7.48(\mathrm{~d}, 2 \mathrm{H}$, $J=7.5 \mathrm{~Hz}), 7.31(\mathrm{~m}, 5 \mathrm{H}), 6.83(\mathrm{~m}, 4 \mathrm{H}), 5.13(\mathrm{~s}, 2 \mathrm{H})$.

${ }^{13}$ C NMR (100.6 MHz, CDCl3): $\delta_{\mathrm{C}}=170.9,169.8,140.9,139.3,139.1,136.8,130.3$, $129.9,129.4,128.7,128.6,127.8,119.8,53.9$.

HRMS (ES+): calcd for $\mathrm{C}_{21} \mathrm{H}_{17} \mathrm{~N}_{4} \mathrm{O}_{3} 373.1301[\mathrm{M}+\mathrm{H}]^{+}$, found $373.1310[\mathrm{M}+\mathrm{H}]^{+}$.

FT-IR (ATR): $v_{\max } 2927,2125,2098,1717,1692,1505,1291,1278,1227$ and $733 \mathrm{~cm}^{-}$ 1. 
${ }^{1}$ H-NMR (400 MHz, CDCl3) Compound4.

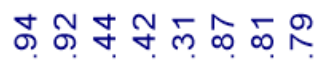

Niño,

$\stackrel{m}{\circ}$
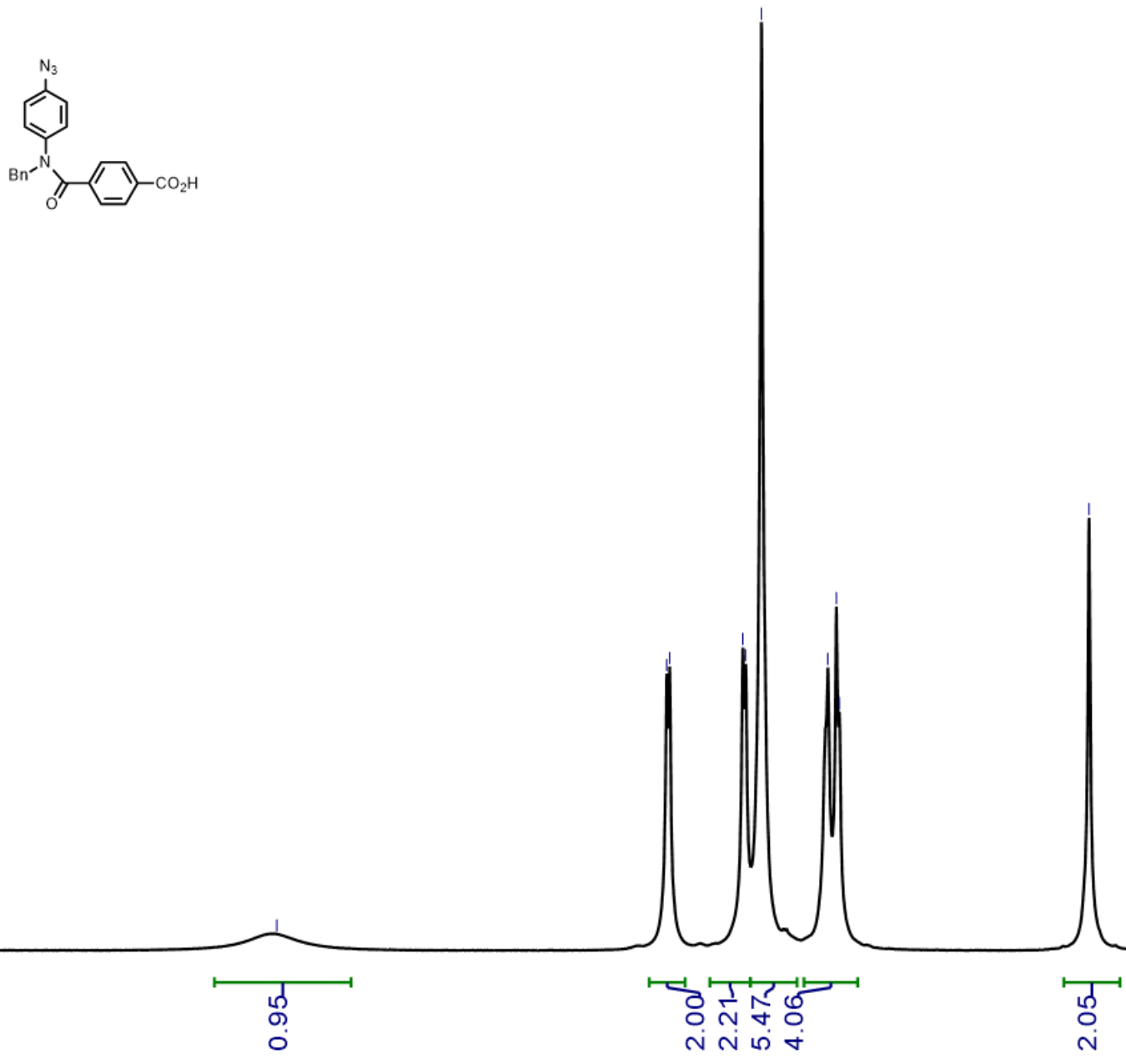

$\begin{array}{lllllllll}2.5 & 12.0 & 11.5 & 11.0 & 10.5 & 10.0 & 9.5 & 9.0 & 8.5\end{array}$ 
${ }^{13} \mathrm{C}-\mathrm{NMR}$ (100.6 MHz, CDCl 3 ) Compound 4.

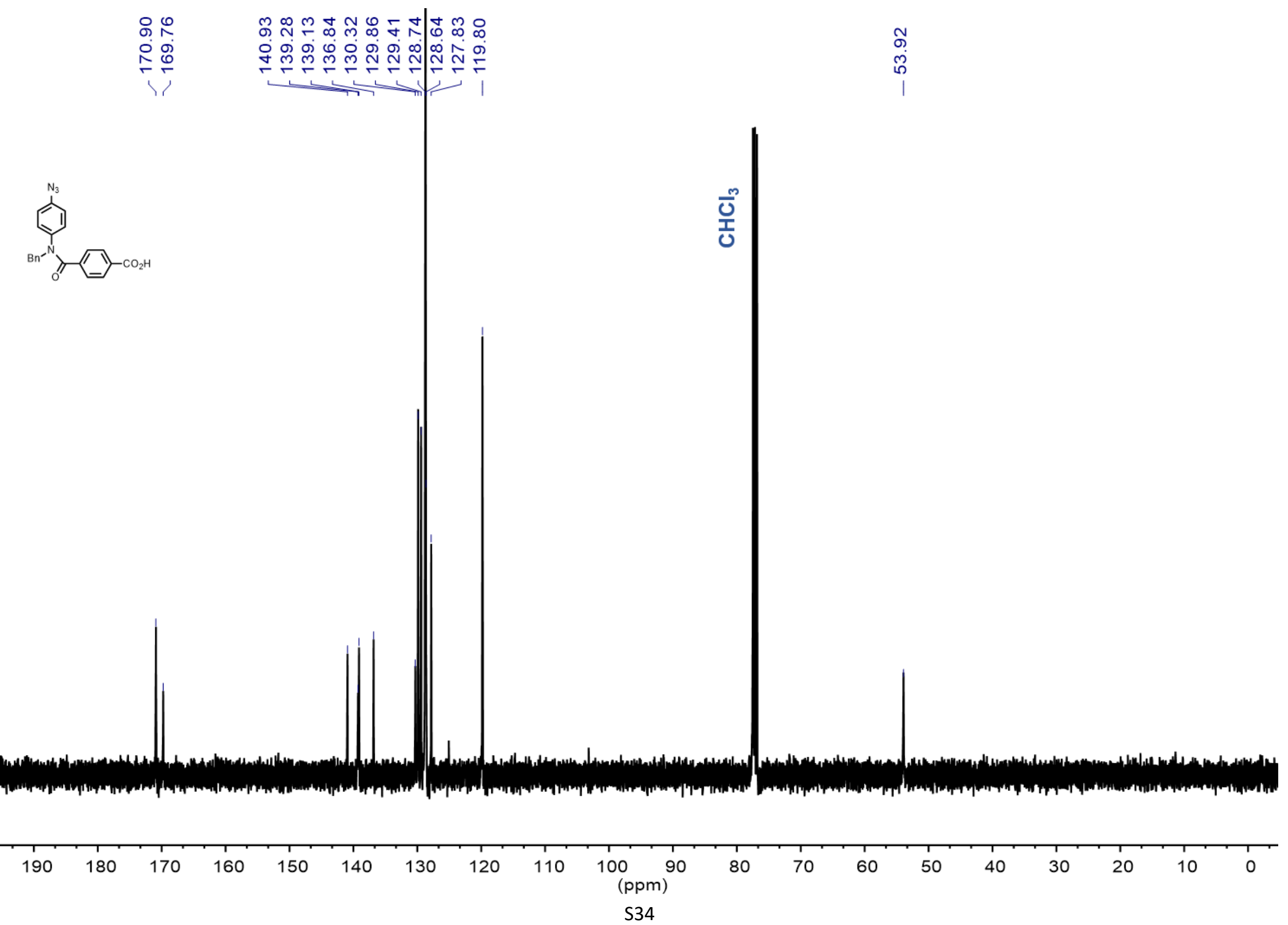




\section{Compound 18}

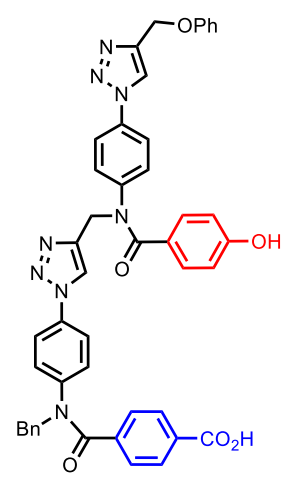

17 (0.060 g, $0.14 \mathrm{mmol}), 4(0.053 \mathrm{~g}, 0.14 \mathrm{mmol}), \mathrm{Cu}\left(\mathrm{CH}_{3} \mathrm{CN}\right)_{4} \mathrm{PF}_{6}(0.005 \mathrm{~g}, 0.01 \mathrm{mmol})$ and TBTA $(0.007 \mathrm{~g}, 0.01 \mathrm{mmol})$ were mixed in a round-bottom flask and THF ( $2 \mathrm{~mL})$ was added under $\mathrm{N}_{2}$. The reaction was stirred overnight at room temperature. Once the reaction was completed, the solvent was evaporated and the crude was purified by flash column chromatography on silica gel (gradient from $0 \%$ to $6 \%$ of $\mathrm{MeOH}$ in $\mathrm{CH}_{2} \mathrm{Cl}_{2}$ ) to afford $18(0.096 \mathrm{~g}, 86 \%)$ as a foam.

${ }^{1}$ H NMR (500 MHz, DMSO-d $\boldsymbol{d}_{\text {) }}$ : $\delta_{\mathrm{H}}=9.89$ (bs, $\left.1 \mathrm{H}\right), 8.86$ (s, 1H), 8.65 (s, 1H), $7.80(\mathrm{~d}$, $2 \mathrm{H}, J=8.0 \mathrm{~Hz}), 7.77(\mathrm{~d}, 2 \mathrm{H}, J=9.0 \mathrm{~Hz}), 7.73(\mathrm{~d}, 2 \mathrm{H}, J=9.0 \mathrm{~Hz}), 7.48(\mathrm{~d}, 2 \mathrm{H}, J=8.0$ $\mathrm{Hz}, 2-\mathrm{H}), 7.39(\mathrm{~d}, 2 \mathrm{H}, J=9.0 \mathrm{~Hz}), 7.29(\mathrm{~m}, 9 \mathrm{H}), 7.19(\mathrm{~d}, 2 \mathrm{H}, J=9.0 \mathrm{~Hz}), 7.05(\mathrm{~d}, 2 \mathrm{H}, J$ $=8.0 \mathrm{~Hz}), 6.96(\mathrm{t}, 1 \mathrm{H}, J=7.5 \mathrm{~Hz}), 6.58(\mathrm{~d}, 2 \mathrm{H}, J=9.0 \mathrm{~Hz}), 5.19(\mathrm{~s}, 2 \mathrm{H}), 5.16(\mathrm{~s}, 2 \mathrm{H})$, $5.15(\mathrm{~s}, 2 \mathrm{H})$.

${ }^{13}$ C NMR (125 MHz, DMSO-d $\left.\mathbf{6}\right): \delta_{\mathrm{C}}=169.3,169.1,166.7,159.0,158.0,144.7,144.0$, $143.9,142.3,139.9,137.0,134.5,134.2,132.0,131.0,129.6,129.1,128.9,128.8,128.6$, $128.5,127.9,127.3,125.7,122.8,121.6,121.0,120.6,120.4,114.7,114.5,60.9,52.6$, 45.4 .

HRMS (ES+): calcd for $\mathrm{C}_{46} \mathrm{H}_{37} \mathrm{~N}_{8} \mathrm{O}_{6} 797.2836[\mathrm{M}+\mathrm{H}]^{+}$, found $797.2609[\mathrm{M}+\mathrm{H}]^{+}$.

FT-IR (ATR): $v_{\max }$ 3147, 2926, 1709, 1635, 1601, 1516, 1278, 1235, 1024, 844, 755 and $732 \mathrm{~cm}^{-1}$. 
${ }^{1}$ H-NMR (500 MHz, DMSO-d6) Compound 18.

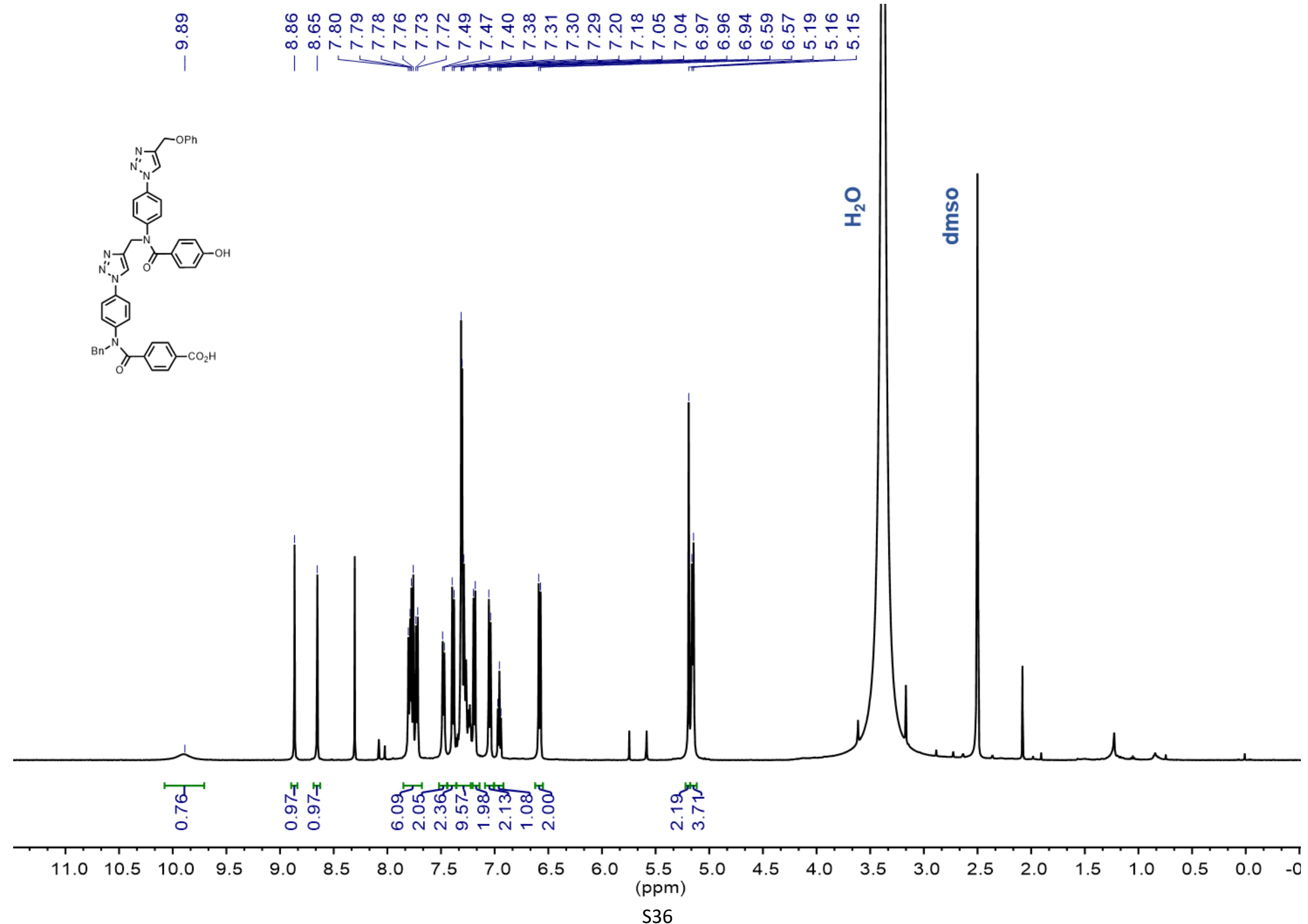


${ }^{13}$ C-NMR (125 MHz, DMSO-d6) Compound 18.

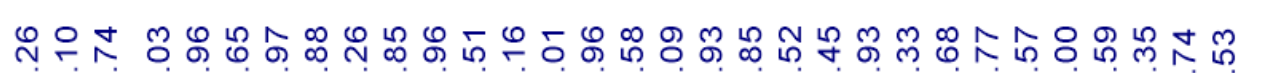

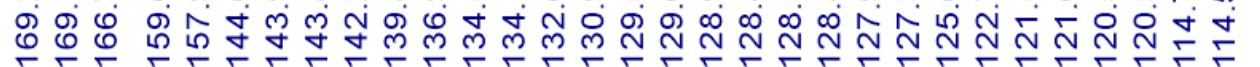

$\checkmark$ 1)
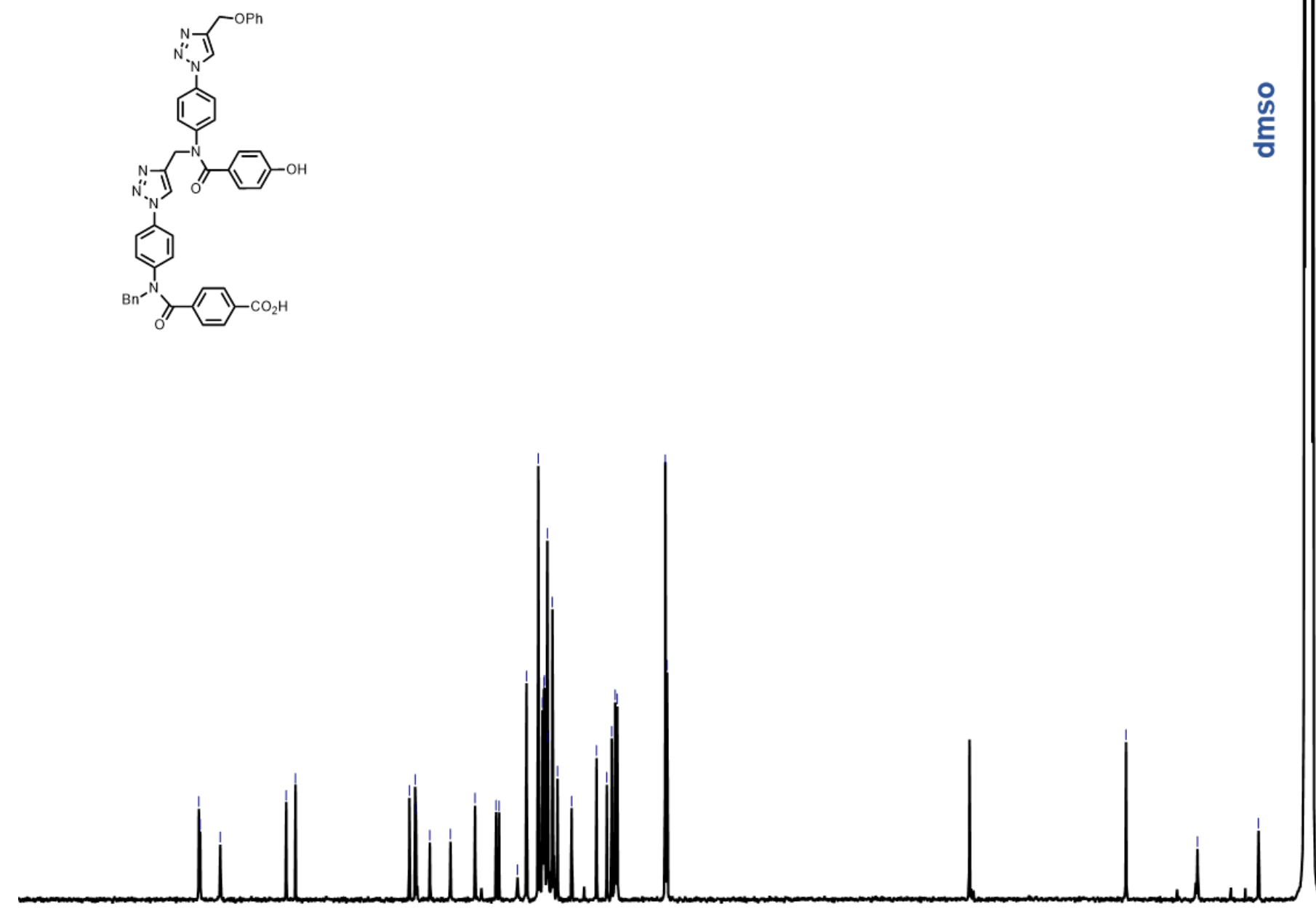

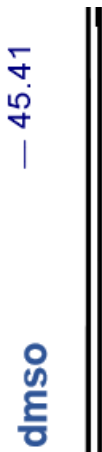

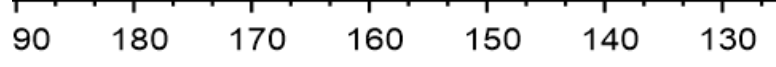

120

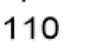

100

90
$(\mathrm{ppm})$

60

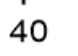




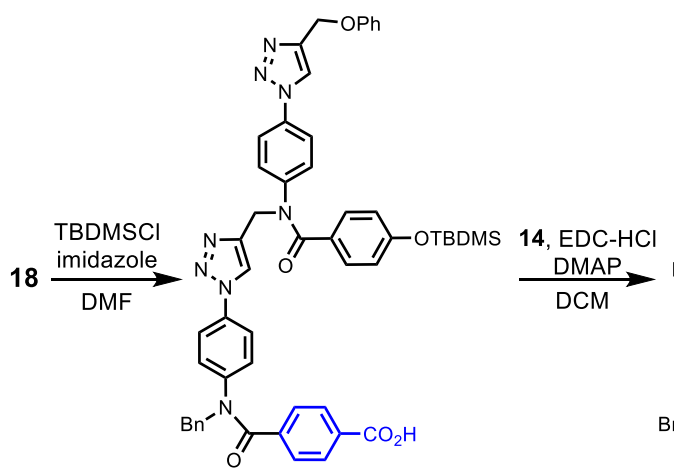

$18 b$
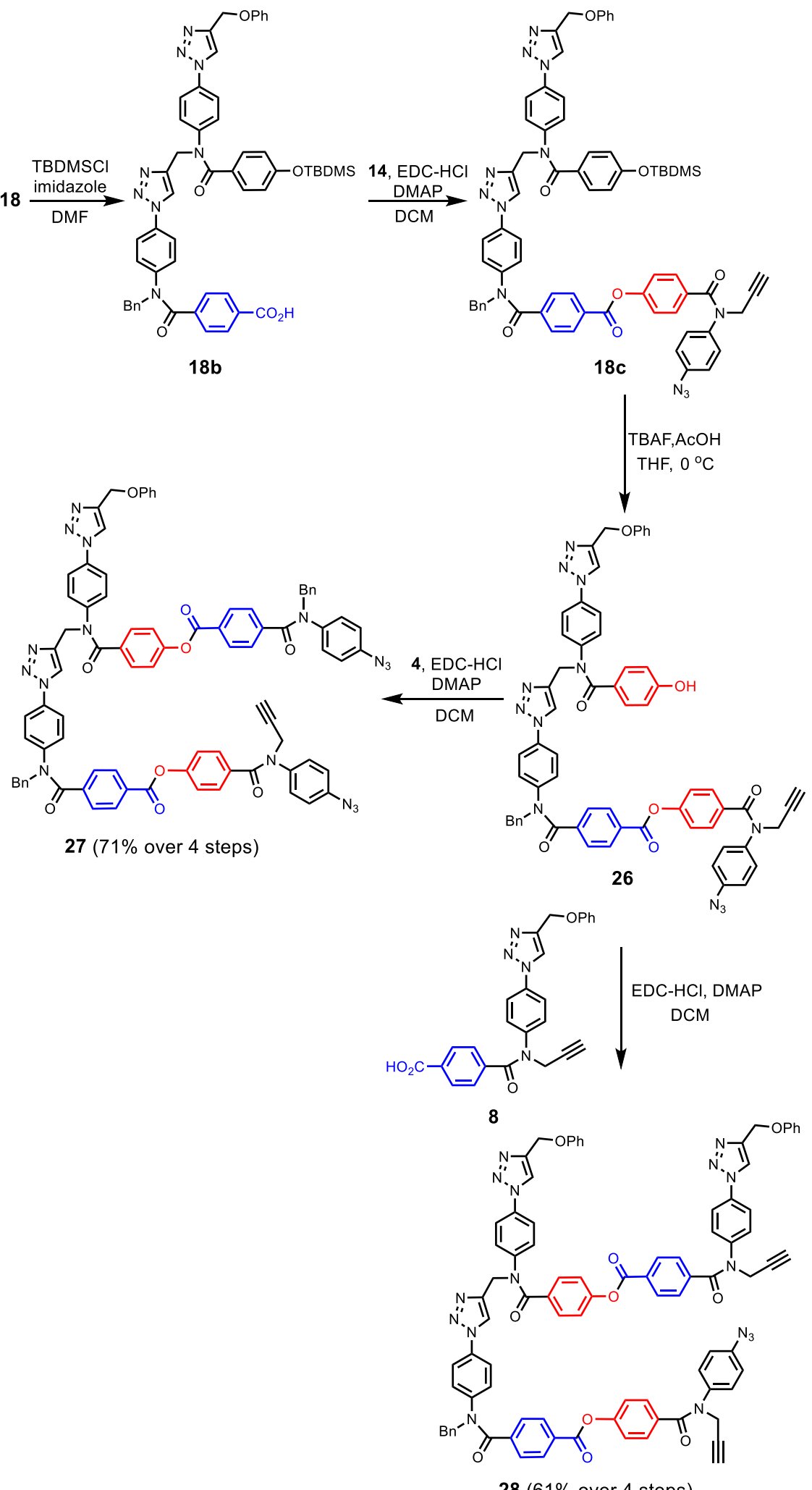

$28(61 \%$ over 4 steps $)$

Scheme S-4. Synthetic scheme of 27 and 28. Compounds 18b, 18c and 26 were not purified and the crude was directly used in the following step. Synthesis of compound $\mathbf{8}$ was previously described. ${ }^{1}$ 


\section{Compound 27}

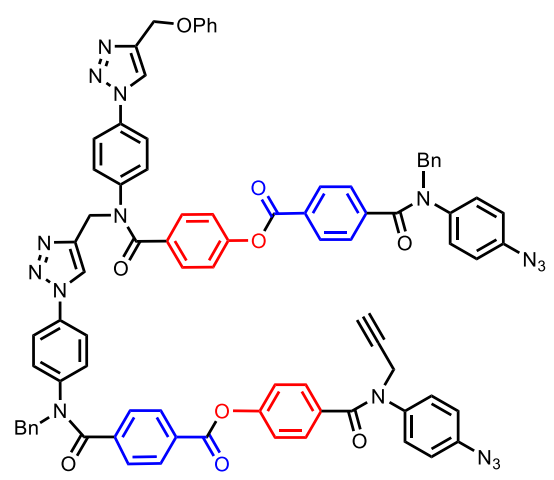

Step 1: Phenol protection

A solution of $18(0.031 \mathrm{~g}, 0.040 \mathrm{mmol})$ in DMF $(1 \mathrm{~mL})$ was treated with imidazole $(0.053$ $\mathrm{g}, 0.78 \mathrm{mmol})$ and TBDMS-Cl $(0.059 \mathrm{~g}, 0.39 \mathrm{mmol})$. After $5 \mathrm{~h}$ of stirring at room temperature, $0.1 \mathrm{M} \mathrm{HCl}_{(\mathrm{aq})}$ solution was added until $\mathrm{pH}=3-4$ and the solution stirred at room temperature for $45 \mathrm{~min}$. The solution was extracted with EtOAc (3x) and the combined organic layer was washed with $5 \% \mathrm{LiCl}$ solution $(3 \mathrm{x}), \mathrm{H}_{2} \mathrm{O}(1 \mathrm{x})$ and brine $(1 \mathrm{x})$, dried with anhydrous $\mathrm{MgSO}_{4}$, filtered, and the solvent evaporated. The obtained residue ( $\mathbf{1 8 b}$ crude) was used in the next step without further purification.

Step 2: Ester coupling

$\mathbf{1 8 b}$ crude $(0.039 \mathrm{mmol}), 14(0.011 \mathrm{~g}, 0.039 \mathrm{mmol}), \mathrm{EDC}-\mathrm{HCl}(0.009 \mathrm{~g}, 0.05 \mathrm{mmol})$ and DMAP $\left(\approx 0.5 \mathrm{mg}, 4 \cdot 10^{-3} \mathrm{mmol}\right)$ were added to a flask. Dry $\mathrm{CH}_{2} \mathrm{Cl}_{2}(1 \mathrm{~mL})$ was added under $\mathrm{N}_{2}$ and the reaction was stirred at room temperature for $2 \mathrm{~h}$. Once finished, the reaction was diluted with EtOAc and washed with $0.1 \mathrm{M} \mathrm{HCl}_{(\mathrm{aq})}$ solution $(2 \mathrm{x}), \mathrm{H}_{2} \mathrm{O}(1 \mathrm{x})$ and brine $(1 \mathrm{x})$. The solution was dried with anhydrous $\mathrm{MgSO}_{4}$, filtered and the solvent evaporated. The obtained residue (18c crude) was used in the next step without further purification.

\section{Step 3: TBAF deprotection}

18 c crude $(0.039 \mathrm{mmol})$ was dissolved in dry THF $(1 \mathrm{~mL})$ under $\mathrm{N}_{2}$ atmosphere. Acetic acid $(2 \mu \mathrm{L}, 0.04 \mathrm{mmol})$ was added and, after cooling down the solution to $0{ }^{\circ} \mathrm{C}$, TBAF (1M in THF, $0.039 \mathrm{~mL}, 0.039 \mathrm{mmol}$ ) was added dropwise. After 10 minutes of stirring at $0{ }^{\circ} \mathrm{C}$, the reaction was quenched with $0.1 \mathrm{M} \mathrm{HCl}_{(\mathrm{aq})}$ solution and diluted with EtOAc. The organic layer was separated and washed with $0.1 \mathrm{M} \mathrm{HCl}_{(\mathrm{aq})}$ solution $(2 \mathrm{x}), \mathrm{H}_{2} \mathrm{O}(1 \mathrm{x})$ and brine (1x). The solution was dried with anhydrous $\mathrm{MgSO}_{4}$, filtered and the solvents evaporated. The obtained residue ( 26 crude) was used in the next step without further purification.

\section{Step 4: Ester coupling}

26 crude (0.039 mmol), compound 4 (0.009 g, $0.04 \mathrm{mmol})$, EDC-HCl (0.009 g, 0.05 mmol) and DMAP $\left(\approx 0.5 \mathrm{mg}, 4 \cdot 10^{-3} \mathrm{mmol}\right)$ were added to a flask. Dry $\mathrm{CH}_{2} \mathrm{Cl}_{2}(1 \mathrm{~mL})$ was added under $\mathrm{N}_{2}$ and the reaction was stirred at room temperature for $2 \mathrm{~h}$. Once finished, the reaction was diluted with EtOAc and washed with $0.1 \mathrm{M} \mathrm{HCl}_{(\mathrm{aq})}$ solution 
(2x), $\mathrm{H}_{2} \mathrm{O}(1 \mathrm{x})$ and brine (1x). The solution was dried with anhydrous $\mathrm{MgSO}_{4}$, filtered and the solvent evaporated. The obtained residue was purified by flash column chromatography on silica gel (gradient from $0 \%$ to $3 \%$ of $\mathrm{MeOH}$ in $\mathrm{CH}_{2} \mathrm{Cl}_{2}$ ) to afford 27 $(0.040 \mathrm{~g}, 71 \%)$ as a yellow foam.

${ }^{1}$ H NMR (400 MHz, CDCl 3$): \delta_{\mathrm{H}}=8.14(\mathrm{~s}, 1 \mathrm{H}), 7.99(\mathrm{~s}, 1 \mathrm{H}), 7.97(\mathrm{~d}, 2 \mathrm{H}, J=8.5 \mathrm{~Hz})$, $7.93(\mathrm{~d}, 2 \mathrm{H}, J=8.5 \mathrm{~Hz}), 7.63(\mathrm{~d}, 2 \mathrm{H}, J=9.0 \mathrm{~Hz}), 7.56(\mathrm{~d}, 2 \mathrm{H}, J=9.0 \mathrm{~Hz}), 7.46(\mathrm{~d}, 2 \mathrm{H}$, $J=8.5 \mathrm{~Hz}), 7.40(\mathrm{~d}, 2 \mathrm{H}, J=8.5 \mathrm{~Hz}), 7.38-7.28(\mathrm{~m}, 18 \mathrm{H}), 7.11(\mathrm{~d}, 2 \mathrm{H}, J=8.5 \mathrm{~Hz}), 7.01$ $(\mathrm{m}, 9 \mathrm{H}, 3-\mathrm{H}), 6.91(\mathrm{~d}, 2 \mathrm{H}, J=8.5 \mathrm{~Hz}), 6.85(\mathrm{~d}, 2 \mathrm{H}, J=8.5 \mathrm{~Hz}), 6.77(\mathrm{~d}, 2 \mathrm{H}, J=8.5 \mathrm{~Hz})$, $5.28(\mathrm{~s}, 2 \mathrm{H}), 5.18(\mathrm{~s}, 2 \mathrm{H}), 5.17(\mathrm{~s}, 2 \mathrm{H}), 5.09(\mathrm{~s}, 2 \mathrm{H}), 4.63(\mathrm{~d}, 2 \mathrm{H}, J=2.5 \mathrm{~Hz}), 2.25(\mathrm{t}, 1 \mathrm{H}$, $J=2.5 \mathrm{~Hz})$.

${ }^{13}$ C NMR (100.6 MHz, CDCl3): $\delta_{\mathrm{C}}=169.5,169.4,169.3,169.2,163.8,163.7,158.2$, 152.3 and 152.0, 145.5, 144.6, 144.4, 141.2, 140.8, 139.5, 139.3, 139.1, 136.9, 136.7, 135.4, 135.3, 132.6, 132.4, 130.6, 130.5, 130.4, 130.0, 129.9, 129.7, 129.5, 129.2, 128.9, $128.8,128.6,128.0,127.9 .125 .1,122.2,121.5,121.5,121.5,121.2,121.1,120.8,120.0$, $119.8,114.9,78.8,72.8,62.0,53.9,53.9,46.6,40.1$.

HRMS (ES+): calcd for $\mathrm{C}_{83} \mathrm{H}_{61} \mathrm{~N}_{16} \mathrm{O}_{9} 1425.4807[\mathrm{M}+\mathrm{H}]^{+}$, found $1425.9059[\mathrm{M}+\mathrm{H}]^{+}$.

FT-IR (ATR): $v_{\max } 2926,2124,2094,1739,1644,1518,1505,1294,1202,843,753$ and $729 \mathrm{~cm}^{-1}$. 
${ }^{1}$ H-NMR (400 MHz, CDCl $)$ Compound 27.

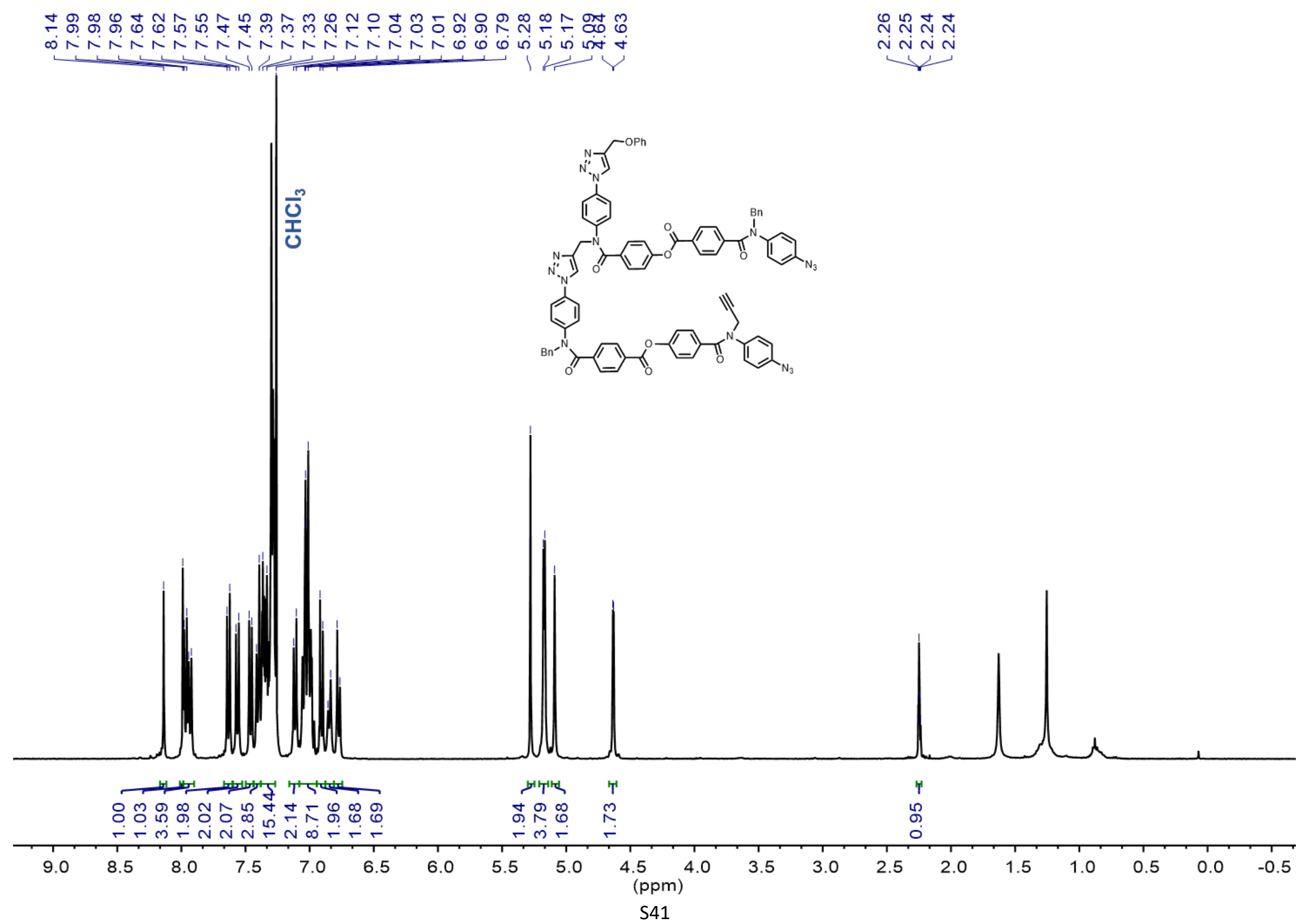


${ }^{13} \mathrm{C}-\mathrm{NMR}$ (100.6 MHz, CDCl 3$)$ Compound 27.

$\forall-\frac{1}{\sim}$

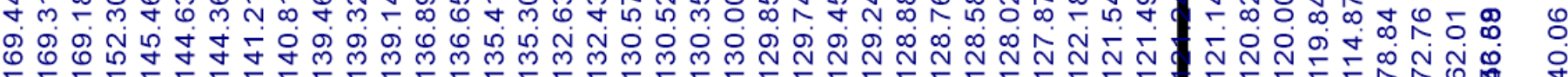

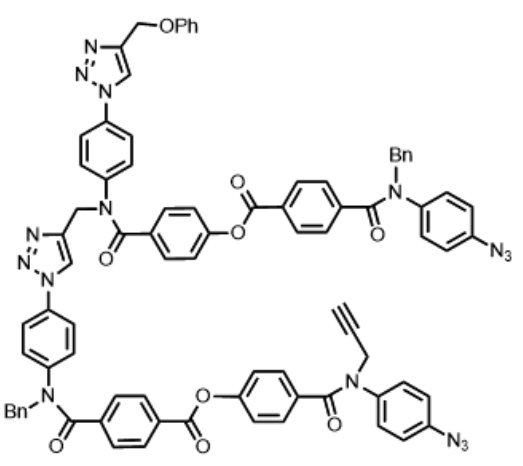

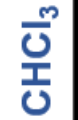

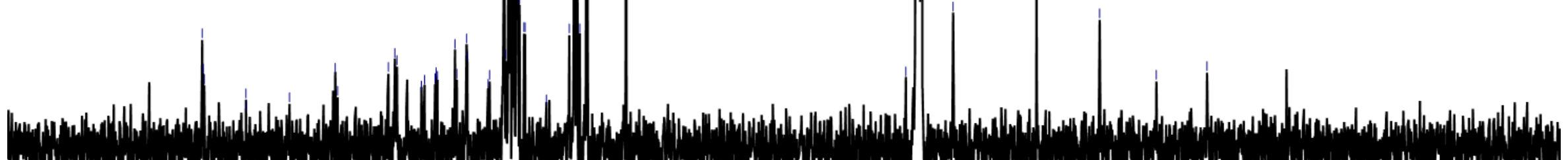

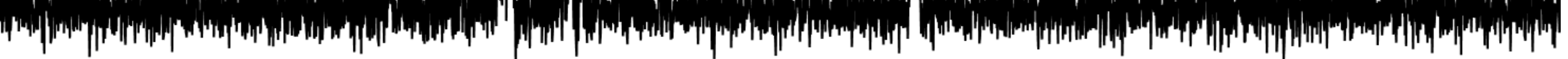

\begin{tabular}{|c|c|c|c|c|c|c|c|c|c|c|c|c|c|c|c|c|c|c|}
\hline 190 & 180 & 170 & 160 & 150 & 140 & 130 & 120 & 110 & $\begin{array}{c}100 \\
(\mathrm{ppm})\end{array}$ & 80 & 70 & 60 & 50 & 40 & 30 & 20 & 10 & 0 \\
\hline
\end{tabular}




\section{Compound 28}

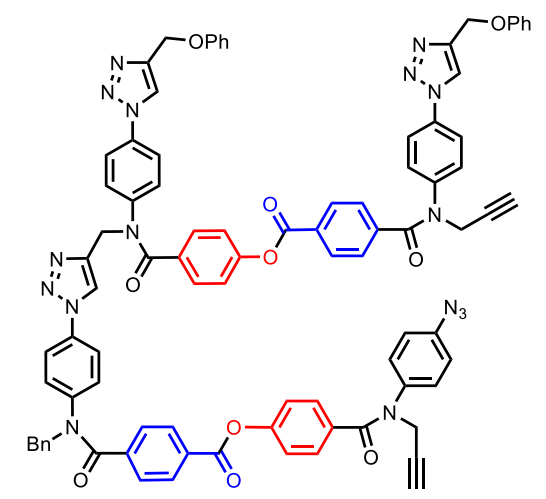

The same procedure used for the synthesis of $\mathbf{2 7}$ was used for $\mathbf{2 8}$. In the last step compound $\mathbf{8}$ was used instead of compound $\mathbf{4}$. The obtained residue was purified by flash column chromatography on silica gel (gradient from $0 \%$ to $3 \%$ of $\mathrm{MeOH}$ in $\mathrm{CH}_{2} \mathrm{Cl}_{2}$ ) to afford compound $13(0.047 \mathrm{~g}, 61 \%)$ as a yellow foam.

${ }^{1}$ H NMR (500 MHz, CDCl $): \delta_{\mathrm{H}}=8.14(\mathrm{~s}, 1 \mathrm{H}), 8.00(\mathrm{~s}, 1 \mathrm{H}), 7.99(\mathrm{~s}, 1 \mathrm{H}), 7.96(\mathrm{~d}, 4 \mathrm{H}$, $\mathrm{J}=8.0 \mathrm{~Hz}), 7.66(\mathrm{~d}, 2 \mathrm{H}, J=9.0 \mathrm{~Hz}), 7.63(\mathrm{~d}, 2 \mathrm{H}, J=9.0 \mathrm{~Hz})$, ), $7.56(\mathrm{~d}, 2 \mathrm{H}, J=9.0 \mathrm{~Hz})$, $7.46(\mathrm{~m}, 4 \mathrm{H}), 7.39-7.27(\mathrm{~m}, 17 \mathrm{H}), 7.11(\mathrm{~d}, 2 \mathrm{H}, J=8.5 \mathrm{~Hz}), 7.01(\mathrm{~m}, 12 \mathrm{H}), 6.90(\mathrm{~d}, 2 \mathrm{H}, J$ $=8.5 \mathrm{~Hz}), 5.27(\mathrm{~s}, 2 \mathrm{H}), 5.26(\mathrm{~s}, 2 \mathrm{H}), 5.17(\mathrm{~s}, 2 \mathrm{H}), 5.16(\mathrm{~s}, 2 \mathrm{H}), 4.72(\mathrm{~d}, 2 \mathrm{H}, J=2.5 \mathrm{~Hz})$, $4.63(\mathrm{~d}, 2 \mathrm{H}, J=2.5 \mathrm{~Hz}), 2.31(\mathrm{t}, 1 \mathrm{H}, J=2.5 \mathrm{~Hz}), 2.25(\mathrm{t}, 1 \mathrm{H}, J=2.5 \mathrm{~Hz})$.

${ }^{13}$ C NMR (125 MHz, CDCl 3$): \delta_{\mathrm{C}}=169.4,169.3,169.2,169.0,163.7,163.6,158.2$, 158.2, 152.2, 152.0, 145.6, 145.4, 144.6, 144.3, 143.0, 142.5, 140.8, 140.0, 139.4, 139.3, $136.7,135.9,135.4,135.3,132.6,132.5,130.6,130.6,130.5,130.3,130.0,130.0,129.8$, $129.3,129.2,129.2$, 128.9, 128.9, 128.7, 128.6, 128.0, 122.2, 121.6, 121.5, 121.5, 121.4, $121.2,121.1,120.8,120.8,120.0,114.9,114.8,78.8,78.3,73.3,72.8,62.0,61.9,53.9$, $46.6,40.1,39.8$.

HRMS (ES+): calcd for $\mathrm{C}_{88} \mathrm{H}_{65} \mathrm{~N}_{16} \mathrm{O}_{10} 1505.5070[\mathrm{M}+\mathrm{H}]^{+}$, found $1505.4907[\mathrm{M}+\mathrm{H}]^{+}$.

FT-IR (ATR): $v_{\max } 3298,3011,2928,2124,2095,1739,1643,1600,1518,1505,1261$, $1237,1201,1165$ and $748 \mathrm{~cm}^{-1}$. 
${ }^{1}$ H-NMR (500 MHz, CDCl3) Compound 28.

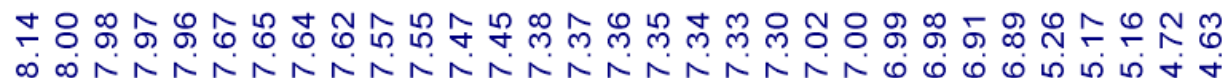

$\bar{m} \stackrel{n}{N}$

in

$\longrightarrow$

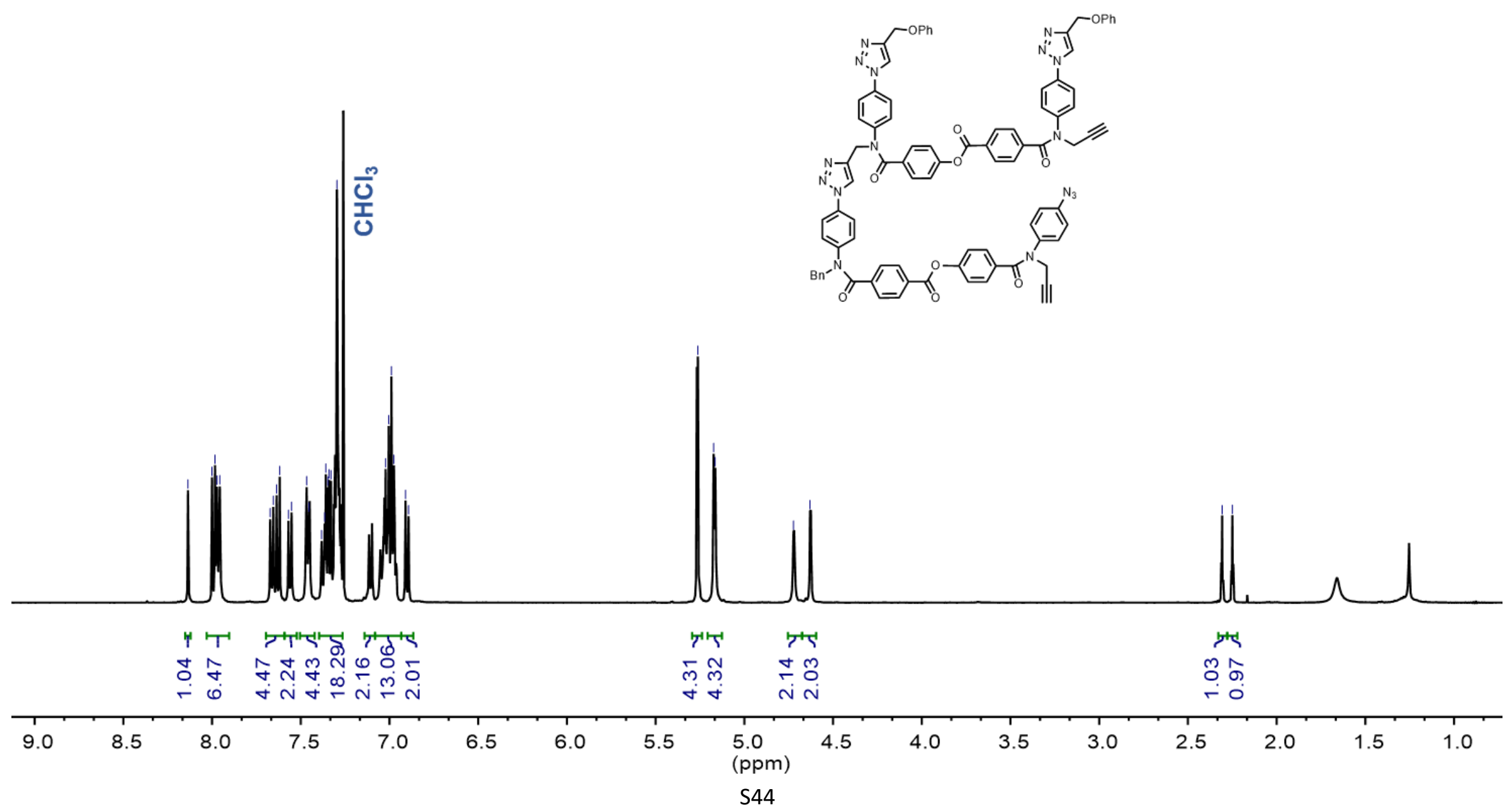


${ }^{13} \mathrm{C}-\mathrm{NMR}\left(125 \mathrm{MHz}, \mathrm{CDCl}_{3}\right)$ Compound 28.

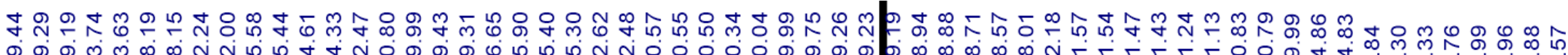

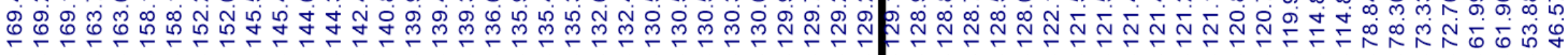

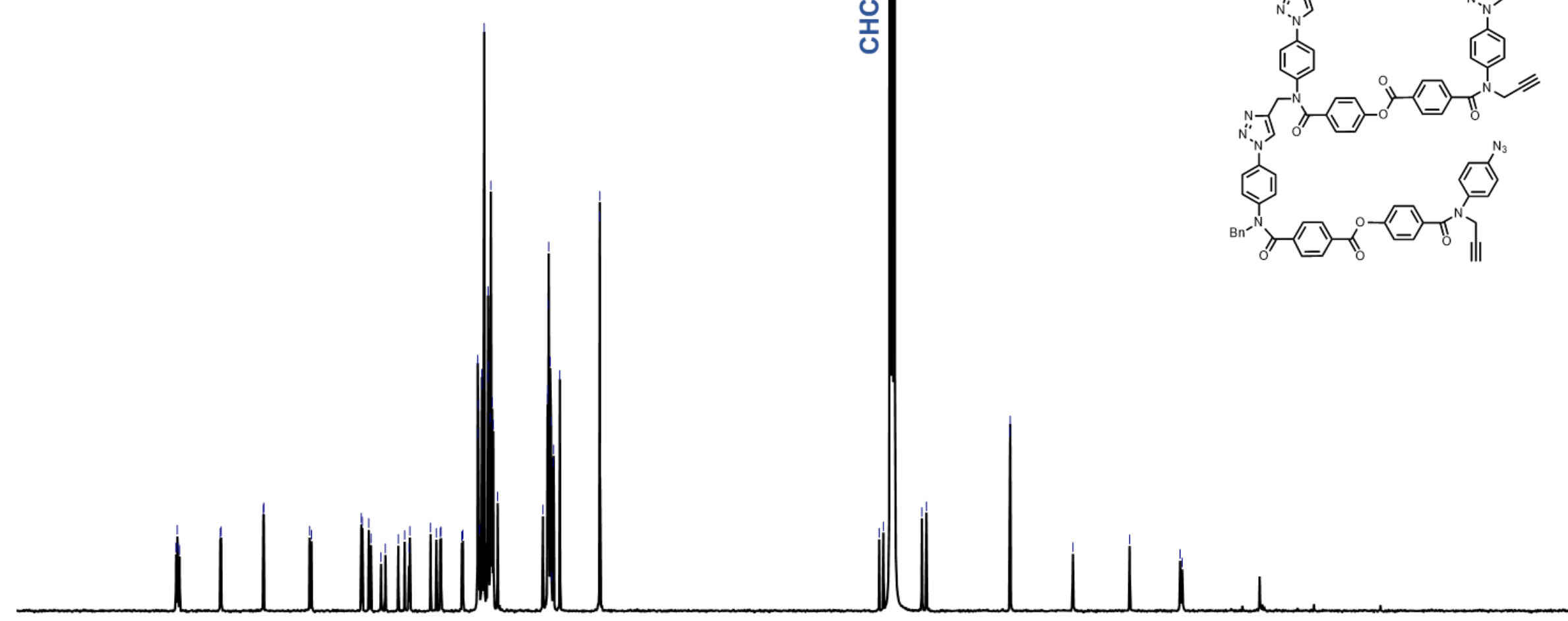




\section{Compound 36}

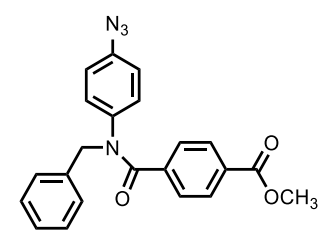

$100 \mu \mathrm{l}$ of $\mathrm{MeOH}$ were added to a stirring solution of $4(0.020 \mathrm{~g}, 0.054 \mathrm{mmol}), \mathrm{EDC}-\mathrm{HCl}(0.012$ $\mathrm{g}, 0.063 \mathrm{mmol})$ and DMAP $(0.01 \mathrm{~g}, 0.01 \mathrm{mmol})$ in dry $\mathrm{CH}_{2} \mathrm{Cl}_{2}$. After $2 \mathrm{~h}$ stirring at room temperature, the reaction mixture was washed with $5 \% \mathrm{HCl}_{(\mathrm{aq})}(2 \mathrm{x}), \mathrm{H}_{2} \mathrm{O}(1 \mathrm{x})$ and brine $(1 \mathrm{x})$, dried over $\mathrm{MgSO}_{4}$ and evaporated under reduced pressure. The crude was purified on silica column ( 0 to $40 \%$ gradient of EtOAc in Pet. Ether) and the pure product was isolated as a pale-yellow wax (0.049 mmol, 90\%).

${ }^{1}$ H NMR (400 MHz, CDCl 3$): ~ \delta_{\mathrm{H}}=7.85(\mathrm{~d}, 2 \mathrm{H}, J=8.0 \mathrm{~Hz}), 7.37(\mathrm{~d}, 2 \mathrm{H}, J=8.0 \mathrm{~Hz}), 7.28(\mathrm{~m}$, $5 \mathrm{H}), 6.84(\mathrm{~d}, 2 \mathrm{H}, J=8.5 \mathrm{~Hz}), 6.77(\mathrm{~d}, 2 \mathrm{H}, J=8.5 \mathrm{~Hz}), 5.09(\mathrm{~s}, 2 \mathrm{H}), 3.87(\mathrm{~s}, 3 \mathrm{H})$.

${ }^{13} \mathbf{C}$ NMR (100.6 MHz, CDCl 3$): ~ \delta_{\mathrm{C}}=169.7,166.4,140.3,139.5,139.0,137.0,131.1,129.4$, $129.3,128,8,128.7,128.6,127.8,119.8,53.9,52.4$.

HRMS (ES+): calcd for $\mathrm{C}_{22} \mathrm{H}_{19} \mathrm{~N}_{4} \mathrm{O}_{3} 387.1457[\mathrm{M}+\mathrm{H}]^{+}$, found $387.1453[\mathrm{M}+\mathrm{H}]^{+}$.

FT-IR (ATR): $v_{\max }$ 2950, 2929, 2125, 2094, 1722, 1647, 1505, 1277, 1109 and $721 \mathrm{~cm}^{-1}$. 
${ }^{1}$ H-NMR (400 MHz, CDCl3) Compound 36.

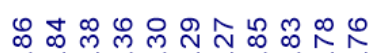

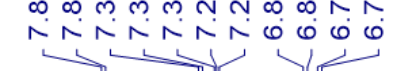
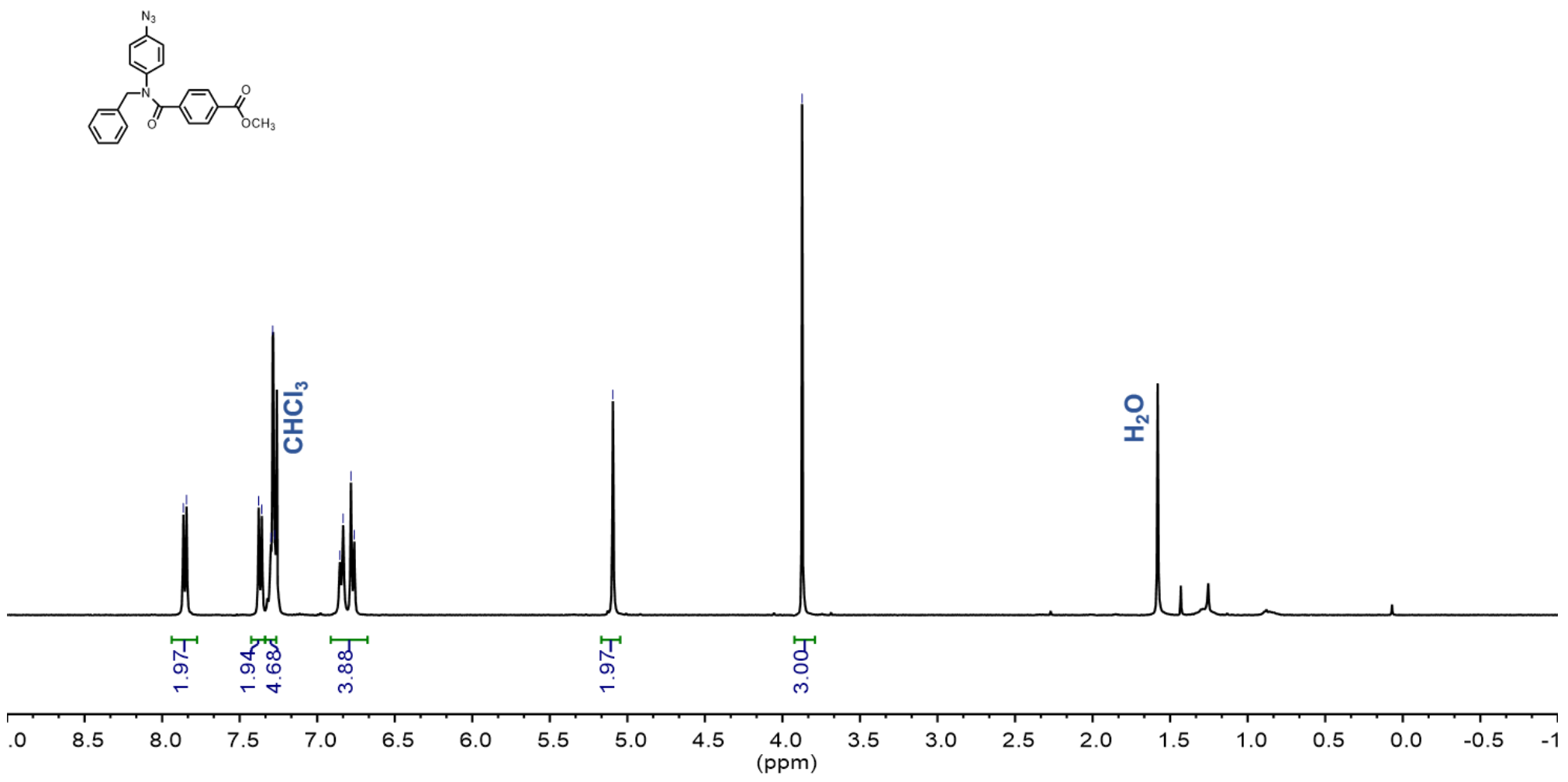

${ }^{13} \mathrm{C}$ NMR (100.6 MHz, CDCl3) Compound 36.

S47 

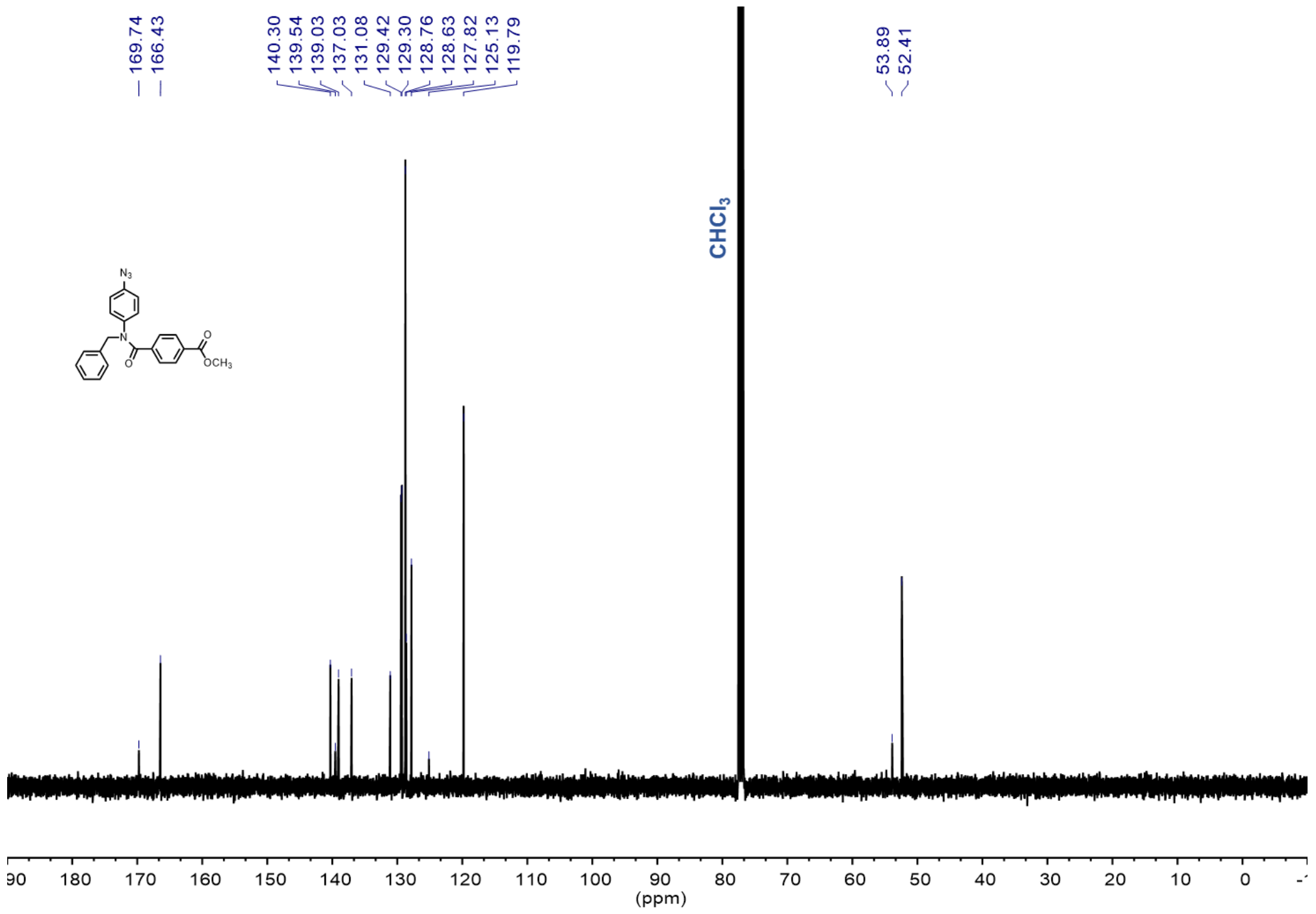

S48 


\section{Compound 38}

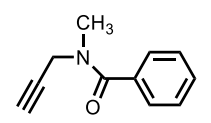

Benzoic acid (1.00 g, $8.19 \mathrm{mmol})$, EDC-HCl (1.88 g, $9.83 \mathrm{mmol})$ and DMAP (0.104 g, 0.851 mmol) were dissolved in $17 \mathrm{~mL}$ of dry $\mathrm{CH}_{2} \mathrm{Cl}_{2} .830 \mu \mathrm{l}(9.83 \mathrm{mmol})$ of $\mathrm{N}$-methyl propargylamine were added to the mixture, which was then stirred for $1 \mathrm{~h}$. After this time the mixture was washed with $5 \% \mathrm{HCl}_{(\mathrm{aq})}(2 \mathrm{x}), \mathrm{H}_{2} \mathrm{O}(1 \mathrm{x})$ and brine $(1 \mathrm{x})$, dried over $\mathrm{MgSO}_{4}$ and evaporated under reduced pressure. The crude was purified on silica column ( 0 to $5 \%$ gradient of $\mathrm{MeOH}$ in $\mathrm{CH}_{2} \mathrm{Cl}_{2}$ ) and the pure product was isolated as a colourless oil at room temperature that is solid at $4{ }^{\circ} \mathrm{C}(1.28 \mathrm{~g}, 90 \%)$.

${ }^{1} \mathbf{H}$ NMR (400 MHz, CDCl 3$): ~ \delta_{H}=7.48-7.42(\mathrm{~m}, 5 \mathrm{H}), 4.38$ and 4.01(bs, 2H), 3.15 and 3.07 (bs, 3H), $2.32(\mathrm{bs}, 1 \mathrm{H})$.

${ }^{13}$ C NMR (100.6 MHz, CDCl3): $\delta_{C}=171.4,135.6,130.1,128.6,127.2,78.6,73.2,72.3,41.7$, $36.9,36.6,33.0$.

HRMS (ES+): calcd for $\mathrm{C}_{11} \mathrm{H}_{11} \mathrm{NO}_{-} \mathrm{H}^{+}$174.0919, found 174.0917.

FT-IR (ATR): $v_{\max }$ 3289, 3230, 2922, 2115, 1627, 1445, 1394, 1263, 1068, 1026, 932, 789. 
${ }^{1} \mathrm{H}-\mathrm{NMR}$ (400 MHz, CDCl 3 ) Compound 38.

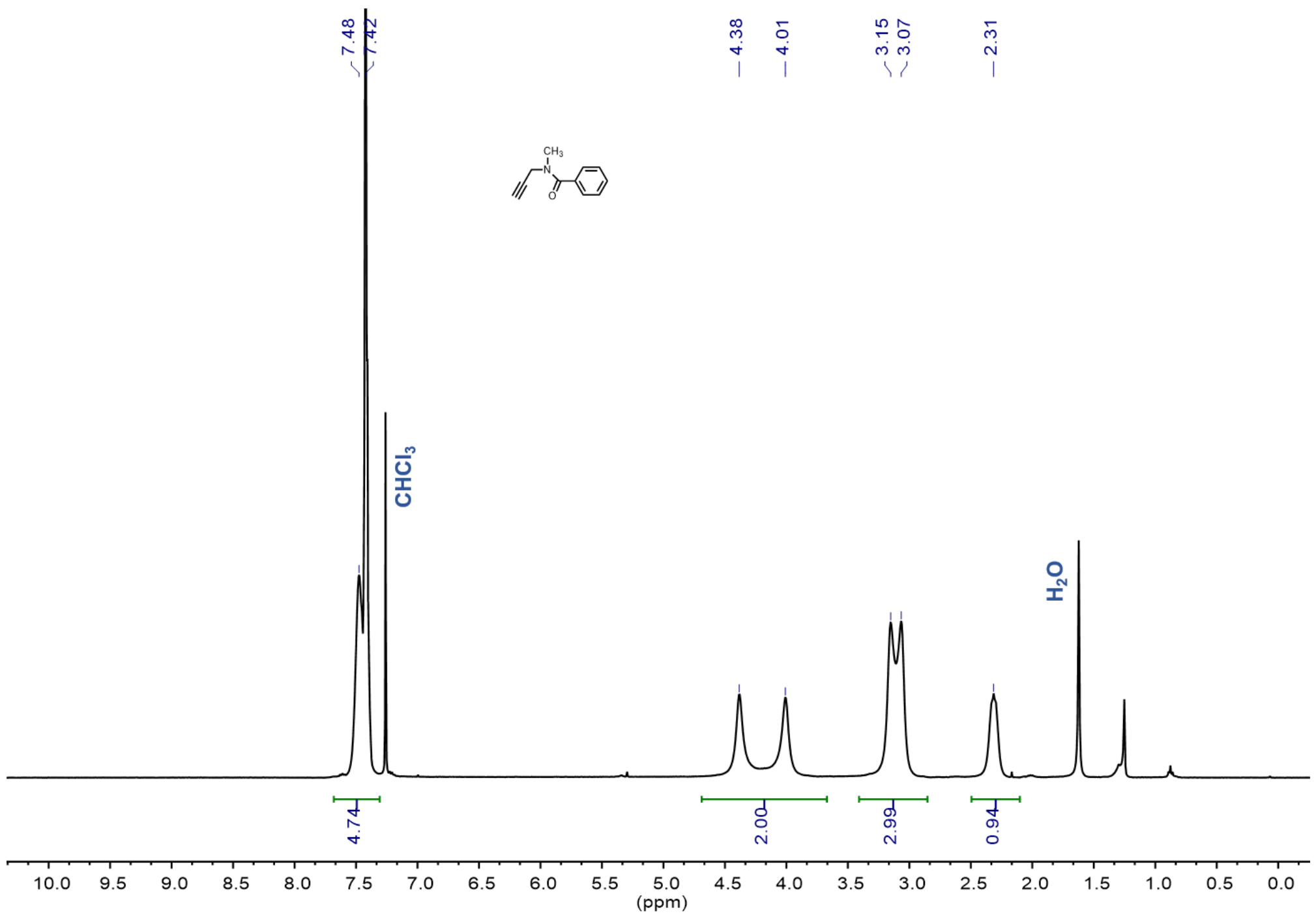

S50 
${ }^{13} \mathrm{C}$ NMR (100.6 MHz, CDCl 3$)$ Compound 38.

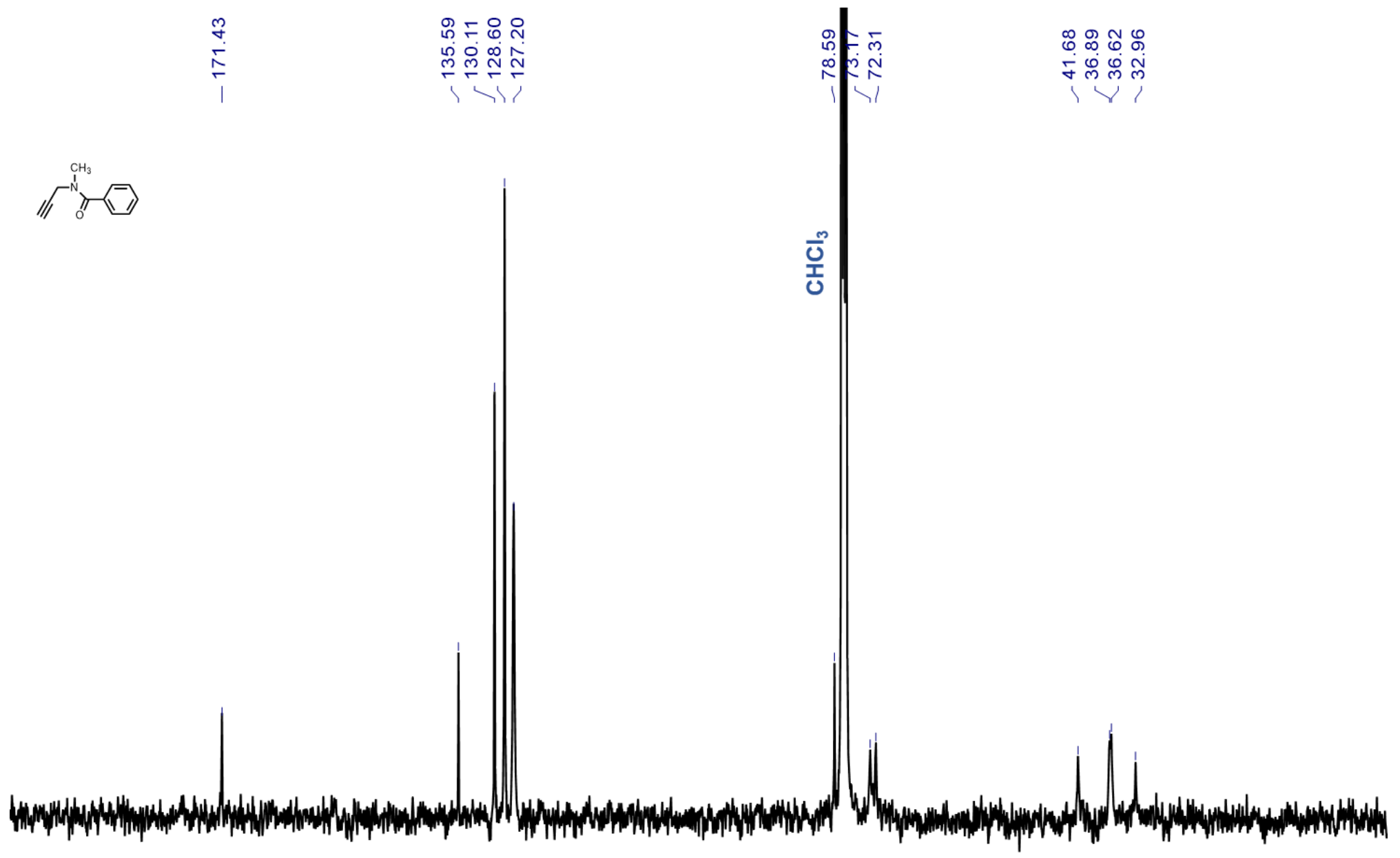

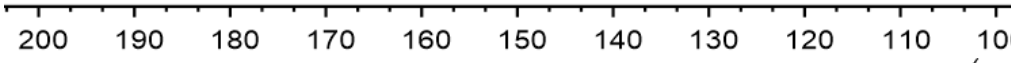
$(\mathrm{ppm})$

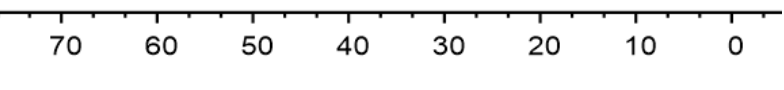




\section{References}

(S1) Núñez-Villanueva, D.; Ciaccia, M.; Iadevaia, G.; Sanna, E.; Hunter, C. A. Sequence information transfer using covalent template-directed synthesis. Chem. Sci. 2019, 10, 5258. 